\title{
La fiscalización administrativa en el ordenamiento peruano: de la heterogeneidad a la regulación común $n^{(*)\left(^{* *}\right)}$
}

\author{
Administrative oversight in the Peruvian legal system: from heterogeneity \\ to a common regulation
}

\author{
Lucio Andrés Sánchez Povis ${ }^{(* \star)}$ \\ Pontificia Universidad Católica del Perú (Lima, Perú)
}

\begin{abstract}
Resumen: El presente artículo aborda el marco conceptual general de la fiscalización administrativa y el desarrollo heterogéneo que tuvo a nivel normativo en el ordenamiento peruano hasta el año 2016. Para abordar dicha heterogeneidad, este estudio realiza un recuento de la atención jurídica que recibió esta actividad, por un lado, bajo la Constitución de 1979, de acuerdo a la cual la fiscalización tuvo que ajustarse al modelo de Estado empresario imperante en dicho periodo; y, por el otro, a partir de la Constitución de 1993 hasta la actualidad, donde la fiscalización no solo ha debido fortalecerse y especializarse, sino que ha demandado una transformación organizacional en el Estado peruano, al punto de recogerse disposiciones comunes para el ejercicio de la misma en la Ley No 27444.
\end{abstract}

Palabras clave: Fiscalización Administrativa - Supervisión Administrativa - Estado Empresario - Estado Garante

\begin{abstract}
This article addresses the general conceptual framework of administrative oversight and the heterogeneous development that it had at the regulatory level in the Peruvian system until 2016. To address this heterogeneity, this study recounts the legal attention that this activity has received. On the one hand, under the 1979 Constitution, according to which the administrative oversight had to adjust to the prevailing Entrepreneurial State model in that period. On the other, from the 1993 Constitution to the present day, during which the administrative oversight has not only had to be strengthened and specialized, but has demanded an organizational transformation in the Peruvian State, to the point of collecting common provisions for the exercise of this administrative power in Law No. 27444.
\end{abstract}

Keywords: Administrative Oversight - Administrative Supervision - Entrepreneurial State - Guarantor State

$\left(^{*}\right) \quad$ Nota del Editor: este artículo fue recibido el 3 de mayo de 2020 y su publicación fue aprobada el 12 de mayo de 2020.

$\left({ }^{* *}\right.$ Agradezco a los asistentes de investigación del GIDA-PUCP, Ruth Cacñahuaray, Annie Fetta y Renzo Zárate, por el apoyo en la preparación de este artículo. De igual modo, agradezco a Miguel Ángel Ala, asistente de docencia de Derecho Administrativo en la Pontificia Universidad Católica del Perú, por la revisión final del mismo.

$\left.{ }^{(* *}\right)$ Abogado por la Pontificia Universidad Católica del Perú (PUCP). Master of Laws por University College London (Reino Unido). Profesor de Derecho Administrativo en la Pontificia Universidad Católica del Perú y en la Universidad Nacional Mayor de San Marcos. Miembro Investigador del GIDA PUCP. Vicepresidente de la Comisión de Defensa de la Libre Competencia del INDECOPI. Socio de Sánchez Povis Abogados. 


\section{Introducción}

La necesidad que desde siempre ha tenido la Administración Pública de cerciorarse que los cometidos y obligaciones contenidos en normas, actos, contratos y demás formas jurídicas sean observados debidamente por los administrados, ha exigido y reconocido que ésta ejerza actividades de fiscalización sobre estos últimos ${ }^{(1)}$. La fiscalización administrativa no es sino una manifestación más del poder de policía (Rebollo, 2017, p. 66-79) que se le atribuye a la Administración Pública para que pueda incidir y limitar los derechos e intereses de los particulares, de modo que con su intervención se prevengan incumplimientos (prevención del riesgo), se incentive la observancia del Derecho (cumplimiento) y se informe (eduque) a los particulares respecto a las obligaciones que tienen a su cargo (Sánchez Povis, 2019 , p. 445-466). Sin embargo, el tratamiento normativo sobre el ejercicio de este poder no se ha caracterizado por su uniformidad en el ordenamiento peruano. Por el contrario, por mucho tiempo éste ha estado marcado por la confluencia de distintos marcos normativos, en cada uno de los cuales la fiscalización adoptó distintos moldes de ejercicio, hizo suyas variadas características y se sujetó a condiciones diversas de acuerdo a los bienes jurídicos e intereses que cada régimen tutelaba y, principalmente, al respectivo rol que asumía en cada momento el Estado en la sociedad. El objetivo de este estudio es, precisamente, advertir estos cambios y llamar la atención respecto a la evolución que su carácter instrumental ha tenido a nivel legislativo. Destacaré, principalmente, cómo estos regímenes fueron amoldando el ejercicio de este poder a las transformaciones del Estado peruano y cómo fueron especializando la organización administrativa de este último.

Para cumplir este propósito, y luego de brindar una breve aproximación conceptual a la fiscalización administrativa, el estudio que presento identificará dos marcados periodos en la evolución del tratamiento normativo de esta actividad: una inicial, bajo la vigencia de la Constitución de 1979, y otra que se desarrolla de acuerdo a los nuevos roles del Estado peruano conforme a la Constitución de 1993. Sobre este último periodo, me detendré a explorar los principales regímenes legales que, de forma singular, regularon el ejercicio de esta actividad. Al llevar a cabo esta tarea, me enfocaré en destacar los distintos bienes jurídicos tutelados y cómo la atención del poder público fue evolucionando con el tiempo, enfocándose inicialmente en temas de recaudación y empleo, pasando luego a la supervisión del mercado y la regulación de servicios públicos, para finalmente arribar (tal vez como un nuevo y fresco retorno) a la atención de derechos prestacionales y sociales, al mismo tiempo que el aparato administrativo a cargo de esta actividad se fue especializando. Finalmente, la adopción de un régimen legislativo común sobre fiscalización administrativa en el Texto Único Ordenado de la Ley 27444 - Ley del Procedimiento Administrativo General (TUO LPAG) significará una respuesta al heterogéneo conjunto normativo estudiado, y resumirá en sí mismo las razones por las cuales era necesario recoger contornos mínimos en el ejercicio de esta potestad, conclusión que, además, le da nombre al presente artículo.

Dado que el trabajo que realizaré se apoya, en gran medida, en un recuento histórico del desarrollo normativo de la fiscalización, no quisiera que se le acuse de no ser "científico". Insisto que la exposición que sigue permite evidenciar los contrastes de la supervisión en función al modelo de Estado que se opte y cómo a través de ella podemos otorgarle efectividad no solo al régimen económico (que impulsó la evolución que detallaré en este estudio), sino, también, operatividad a la cláusula de Estado Social recogida, principalmente, en el artículo 43 de la Constitución de 1993. Por tanto, este estudio no es un conjunto de citados normativos y, como tal, aporta a la investigación y al desarrollo académicos.

\section{Sobre el concepto de fiscalización administrativa y su carácter "maleable"}

La actividad de fiscalización (también conocida como actividad de inspección o supervisión administrativa) es definida como aquella actividad que permite a la Administración comprobar y examinar que la conducta de los administrados o ciertas realidades se ajustan a los deberes, prohibiciones y limitaciones bajo los que se encuentran sometidos. Así, se ejerce actividad de fiscalización cuando nos encontramos frente a actuaciones que permiten a la Administración "llevar a cabo funciones de comprobación o constatación del cumplimiento de la normativa vigente,

(1) La referencia al cambio del rol del Estado y su paso de uno de carácter prestacional a otro de carácter "garante" es abordado, en dichos términos, por Mir Puigpelat (2004, p. 95-128). Esta denominación ha tenido acogida y desarrollo, sobre todo, por Esteve Pardo (2015, p. 11-39); y del mismo autor en Esteve Pardo (2014, p. 52-54). También véase Parejo Alfonso (2016b). 
incluidas muy especialmente las condiciones y requisitos de orden técnico, consecuencia inherente de la imposición que a determinadas personas, actividades, instalaciones, objetos y productos hacen ciertas normas jurídicas" (Bermejo, 2000, p. 1255). En concreto, la actividad administrativa de inspección busca comprobar que el ejercicio de derechos y obligaciones de un particular se ajusta al ordenamiento jurídico. Para el logro de tal fin, la Administración puede recopilar datos, realizar actividades de vigilancia e investigación (García Ureta, 2006, p. 13-16) e, incluso, puede delegar en los privados el ejercicio de dicha función a efectos de valerse de su experiencia y conocimientos técnicos en una actividad en particular (Canals, 2003; Zegarra, 2016).

A partir de esta definición, se pueden extraer algunos elementos estructurales que identifican a esta actividad. En primer lugar, la finalidad de la fiscalización se enmarca en la verificación de los deberes, prohibiciones y limitaciones de los administrados. De este modo, y en primer orden, corresponde a la fiscalización administrativa la procura de la observancia del Derecho en general, es decir, la concreción material de aquello abstractamente contenido en las normas o en otras formas jurídicas empleadas por la Administración. En segundo lugar, se trata de una actividad material realizada por la Administración hacia los administrados y, por tanto, involucra un hacer fáctico de la autoridad. Esta actuación material tiene lugar mediante el empleo de los instrumentos que le reconoce el ordenamiento jurídico y siempre dentro de los límites que todo ejercicio de poder debe observar. Por último, la inspección no tiene únicamente un carácter meramente instrumental, sino que está ligado necesariamente a la finalidad de verificación (Rebollo, 2017, p. 66-68). Por tanto, la verificación o constatación en sí misma cumple con ser un objetivo de fin público y con tener una razón de ser con independencia de que pueda servir de sustento para el ejercicio de otras potestades (sancionadora, autotutela, entre otras) (Izquierdo, 2019, p. 406).

Como lo he sostenido en otra ocasión, la actividad de inspección, fiscalización o supervisión ha sido estudiada tradicionalmente sobre la base de su carácter represivo por la estrecha relación que guarda con el ejercicio de la potestad sancionadora. Sin embargo, es menester hacer también hincapié en que ésta tiene un carácter preventivo y no solo está atada al ejercicio de aquella potestad (Sánchez Povis, 2019). Así pues, si bien se advierte con razón que la fiscalización está normalmente dirigida a la adopción de una decisión en muchos casos de gravamen o afectación, también puede llevarse a cabo para mejorar la información de la Administración sobre algún asunto y de esta manera establecer criterios de actuación adecuados (Sánchez Morón, 2017, p. 681-682). Es una suerte de instrumento empleado para enlazar dos espacios formalmente separados y que quiebra la asimetría ahí presente mediante el traslado de la información, la orientación y la educación. De esta forma, la fiscalización acompaña al administrado en la identificación de sus obligaciones, la importancia de su cumplimiento y los medios para hacerlo. Se presenta, pues, como un primer paso para el aseguramiento de un "estado de cumplimiento", antes que un analgésico intimidador en un estado permanente de ilegalidad. Más allá de reprimir a un administrado que comete una infracción administrativa, el fin último de la actividad de fiscalización es reducir los incumplimientos de la norma, es decir, que el administrado no vuelva a ser un infractor. Por ello, cabe destacar que, en relación a la finalidad antes mencionada, esta fiscalización debe realizarse de tal forma que permita también atacar las razones de origen que explican la ocurrencia de los incumplimientos y no quedarse limitado en un enfoque represivo (Sánchez Povis, 2019, p. 445-466).

Finalmente, tal vez en mayor magnitud que otras, la actividad de fiscalización aprecia una alta sensibilidad a los cambios y transformaciones que, en su organización administrativa y en sus roles, puede atravesar el Estado. El ejercicio de esta actividad, en primer orden, es el que el Estado contemporáneo ha tenido que reforzar (no en sentido intrusivo) y transformar para adaptar el empleo efectivo de la misma a ese nuevo rol garante que le atribuye el ordenamiento constitucional y que destaca la doctrina ${ }^{(2)}$. Este nuevo contexto público, caracterizado por el surgimiento y promoción de nuevas industrias, el vertiginoso desarrollo y empleo de la tecnología en actividades supervisadas, la regulación del mercado, y el reclamo ciudadano para que la prestación

(2) De acuerdo al artículo 223 del Reglamento de la Ley General de Electricidad, estos funcionarios debían cumplir también con: a) Ser de nacionalidad peruana, con excepción de aquellos que por la naturaleza de su especialidad precisa que sean contratados por el Supremo Gobierno b) Ser de reconocida buena conducta c) Tener especialización y experiencia o práctica profesional durante tres (3) años, por lo menos d) Estar legalmente autorizados para ejercer su profesión e inscritos en el correspondiente Colegio profesional e) Conocer la legislación eléctrica. 
y tutela adecuada de sus derechos sociales sea vigilada por el Estado, exigen de la fiscalización un carácter plenamente maleable y adaptable a todo cambio y a todo reto. Considero que este carácter "maleable" es el que se aprecia, en mayor medida, en el variado tratamiento normativo que la actividad de fiscalización ha experimentado en el ordenamiento peruano en estas últimas cuatro décadas, como detallaré en las secciones siguientes.

\section{La adecuación y el empleo de la fiscalización administrativa a los propósitos del Estado asistencial en el Perú del periodo de 1979 a 1990}

\subsection{Fundamento constitucional de la fiscalización en la Constitución 1979}

Si bien en la Constitución Política del Perú de 1979 no se advierte un apartado que desarrolle concretamente la actividad de supervisión o fiscalización en manos de la Administración, lo cierto es que, de su lectura, pueden encontrarse referencias a la actividad de fiscalización con diferentes denominaciones. No solo ello, pues una aproximación a la fiscalización administrativa en las disposiciones constitucionales de este periodo da cuenta de una actividad que fue instrumentalizada a los propósitos y planes de un tardío modelo de Estado Social (Kresalja, 1999, p. 79). Dado que con este estudio no pretendo agotar las discusiones en torno a la Constitución de 1979, baste llamar la atención respecto a dos cuestiones fundamentales que caracterizaron el tratamiento constitucional de la fiscalización durante este periodo.

Por un lado, la fiscalización administrativa estuvo marcada (y limitada intrínsecamente) por el modelo de Estado empresario instaurado bajo el régimen económico de esta norma fundamental. Para empezar, el artículo 110 de la Constitución de 1979 recogió un régimen económico fundado en "principios de justicia social", donde, de acuerdo al artículo 111, el Estado debía formular "la política económica y social mediante planes de desarrollo" que regulaban la actividad de los demás sectores. Ya de por si esta Constitución aludía a una economía ciertamente planificada, pero a la cual se le añadía otro componente: el Estado ejercía su actividad empresarial de forma directa con el fin de promover la economía del país, prestar servicios públicos y alcanzar los objetivos de desarrollo (artículo 113), pudiendo, por causa de interés social o seguridad nacional, reservarse por ley actividades productivas o de servicios (artículo 114). De este modo, aunque se reconocía la libre iniciativa privada (artículo 115), lo cierto es que esta consagración no devino en el desarrollo de un mercado competitivo, pues el Estado dio suficientes razones para distorsionar estas reglas y desalentar la participación privada en el mismo.

En efecto, como expondré en el punto 3.2 infra, este Estado empresario desplazó la participación privada y creó un contexto nada propicio para el desarrollo de la actividad de fiscalización (mucho menos para su especialización), pues donde finalmente es el Estado el gran agente del mercado, poco importa que él mismo se fiscalice. Asimismo, si la "fiscalización" es realizada por órganos subordinados dentro de la rectoría política de los ministerios, ésta reemplaza su tutela objetiva del fin público por la complicidad como hueste del Estado. El ejercicio mismo de la libertad de empresa estuvo altamente supervisado, a efectos de que no fuera contrario al interés social, claro está, pero también por la prohibición ex ante de los monopolios y oligopolios (artículo 133), con el detalle de la supervisión particular que se ejercía sobre la inversión extranjera y la "transferencia de tecnología foránea" (artículo 137). Por último, este marco constitucional reservó en manos del Estado algunas actividades productivas y la prestación de servicios, en consecuencia, atrás quedó la necesidad de crear organismos reguladores o de contar con una administración especializada en mercado y competencia (aunque escaza referencia se hiciera a ella en el artículo 133), pues estos no existían propiamente como tales.

Por el otro, el marcado celo estatal enfocado (no exclusiva, pero sí primordialmente) en la atención efectiva de los derechos sociales de los particulares, denotó un ejercicio de dicho poder para atender dicha causa; sin embargo, las limitaciones presupuestarias (consecuencia de la participación pública ineficiente en la economía) y la falta de especialización para ejercer esta actividad, terminó prácticamente negando utilidad a la misma. En efecto, la Constitución de 1979 destacó por contener disposiciones que revelaban su preocupación por la protección de la persona humana en distintos ámbitos sociales. Así, muchas disposiciones habilitaban la intervención (mediante fiscalización) del Estado por motivos de salud o sanidad, v.gr. las excepciones a la inviolabilidad del domicilio (artículo 2-7) y la libertad de reunión (artículo 2-10); la prestación adecuada de la seguridad social (artículo 14); la aplicación de la política nacional de salud (artículo 16); y la producción, calidad, uso y comercio de los 
productos alimenticios, farmacéuticos y biológicos (artículo 17). De igual modo, en el ámbito educativo y cultural, el Estado supervisaba la educación con el fin de "asegurar su calidad y eficiencia, según las características regionales y otorgar a todos igualdad de oportunidades" (artículo 24), esto comprendía la supervisión de la educación privada, cooperativa, comunal y municipal, las que no tendrían fines de lucro (artículo 30), así como vigilaba la "conservación, restauración, mantenimiento y restitución" de los yacimientos y restos arqueológicos y demás patrimonio cultural de la nación.

Finalmente, destacaba positivamente la especial atención que se otorgó al derecho al trabajo, donde el Estado supervisaba la proscripción de "cualquier condición que impidiese el ejercicio de los derechos constitucionales de los trabajadores o que desconozca o rebaje su dignidad" (artículo 42); el respeto de la remuneración mínima (artículo 43) y de la jornada de trabajo; el descanso, las vacaciones y la compensación por tiempo de servicios, las gratificaciones, bonificaciones y demás beneficios de ley o del convenio colectivo (artículo 44); así como las medidas sobre higiene y seguridad en el trabajo para la prevención de riesgos profesionales (artículo 47). Sin embargo, todas estas aspiraciones constitucionales quedaron meramente positivizadas y sin asidero alguno en la realidad. La situación de pobreza, desempleo, escaso acceso a la salud, entre otros, dio cuenta que en la práctica el aparato administrativo poco debía fiscalizar, si no había logrado primero asegurar el acceso a prestaciones mínimas sociales.

Por tanto, el desarrollo de la fiscalización en el plano constitucional no se condijo con su ejercicio en la práctica, pues más que una actividad encaminada a salvaguardar el cumplimiento de las obligaciones jurídico-administrativas y su impacto en bienes jurídicos protegidos, su empleo se vio truncado por un modelo de Estado que la volvió inoperante o, en todo caso, que le suprimió su componente de especialización y uso objetivo para el resguardo del interés público. Estábamos, en este periodo, ante una fiscalización obsoleta o sometida a la voluntad política del Estado. Esto explica el escaso desarrollo que recibió a nivel legislativo, como expongo a continuación.

\subsection{Una revisión general del tratamiento legislativo de la fiscalización administrativa durante el periodo del Estado asistencial}

Durante este periodo, la atención legislativa que recibió la fiscalización administrativa estuvo centrada en aspectos principalmente municipales, tributarios y laborales. En lo que respecta al primero de ellos, ésta estuvo caracterizada por una problemática dispersión normativa, sin mayor tratamiento homogéneo sobre su ejercicio en el ámbito local. Por esta razón, no solo resulta difícil su estudio, sino que es complicado también atribuir una caracterización común al desarrollo normativo de la fiscalización a partir de esa experiencia. Sin embargo, una cuestión diferente se advierte en el ámbito tributario. Si las principales características de esta actividad pueden advertirse en una materia específica, esa es sin duda la que estuvo dedicada a cumplir con los fines recaudadores del Estado. Hasta el día de hoy, incluso, es indiscutible el ejercicio de dicho poder en este ámbito y la importancia que se le brinda al mismo. De igual modo, aunque en menor medida, se aprecia un desarrollo de la fiscalización en torno a la tutela del derecho al trabajo, sobre todo obedeciendo al significativo desarrollo que la Constitución de 1979 dio a este último. Sobre estos dos ámbitos de desarrollo me referiré, entonces, en este acápite.

i) Desarrollo normativo y material enfocado en la recaudación tributaria

La principal norma que brindó tratamiento legislativo a la fiscalización administrativa en el rubro tributario durante este periodo fue el Texto Único Ordenado del Código Tributario, aprobado mediante Decreto Supremo 39582-EFC del 30 de diciembre de 1982 (en adelante, DS 395-82-EFC). Este marco normativo, al que posteriormente se le otorgó fuerza de ley mediante el artículo 1 del Decreto Legislativo 300, desarrolló en su artículo 71 el deber y obligación de los contribuyentes y responsables de facilitar las labores de determinación, fiscalización e investigación que realizara la Administración Tributaria. Asimismo, este cuerpo normativo reconoció en su artículo 83 que la Administración Tributaria contaba con amplias facultades para fiscalizar e investigar todos los hechos y datos declarados o que debieron haberlo sido, así como todos los elementos que, directa e indirectamente, determinen o revelen la existencia de hechos imponibles. Conforme a estas amplias atribuciones, el Código Tributario reconocía a la Administración Tributaria facultades para:

- Exigir a los contribuyentes y responsables la exhibición de sus libros, documentos y correspondencia relacionada con hechos que determinen tributación, así como requerir su comparecencia ante las autoridades administrativas.

- Requerir a terceros información y la exhibición de documentos relacionados con hechos que determinen tributación. 
- Practicar inspecciones en los establecimientos o locales en que se desarrollen actividades económicas, así como en los inmuebles o medios de transporte relacionados con tributos específicos.

Como es puntualizado también al día de hoy, ninguna persona natural o jurídica podía negarse a suministrar a la Administración Tributaria la información que ésta solicitara para precisar y esclarecer la situación económica o financiera de los contribuyentes. Por otro lado, de acuerdo con el artículo 87 de la misma norma, la Administración Tributaria se encontraba facultada para fiscalizar también las liquidaciones realizadas por los contribuyentes y las declaraciones que estos hubieran presentado, en la forma que establecía el mismo Código Tributario y las demás leyes tributarias contemporáneas.

Como se aprecia de la principal normativa desarrollada, el régimen tributario de fiscalización establecía las obligaciones de los contribuyentes y responsables, pero no desarrollaba de igual manera los derechos de los mismos ni las formalidades o garantías que debían observar estos supervisores durante el ejercicio de dicha función, como sí lo hace la norma tributaria actual, lo cual evidenciaba cierta desprotección hacia los contribuyentes. No obstante, es importante rescatar que, de acuerdo con los artículos 119 y siguientes del DS 395-82-EFC, existían recursos administrativos (reclamación y apelación) mediante los cuales el contribuyente o administrado podía cuestionar ciertos actos de la Administración Tributaria y, de esta manera, defenderse respecto a las ilegalidades cometidas por ésta. Todo esto, dentro de un amplio desarrollo de facultades con las que contaba la Administración Tributaria en el marco de una fiscalización, las cuales abarcaban diversas acciones con el fin de determinar o revelar la existencia de hechos imponibles. De esta manera, se buscaba verificar el correcto cumplimiento de la normativa tributaria.

Por lo tanto, se puede concluir que el régimen tributario de fiscalización durante este periodo otorgaba significativos poderes a la Administración Tributaria a efectos de cumplir con su objetivo recaudador. A pesar de no desarrollar los derechos que asistían a los administrados supervisados y las formalidades a ser observadas por los fiscalizadores, la normativa tributaria se preocupó por recoger recursos administrativos a través de los cuales los contribuyentes pudieran cuestionar los actos de la Administración Tributaria. Esto, en parte, suplió la seguridad jurídica de los administrados respecto de las facultades ejercidas por la Administración Tributaria en el marco de una fiscalización. No era el régimen más adecuado y garante, desde luego, pues dejaba en manos de los procedimientos recursivos la evaluación de posibles ilegalidades cometidas durante la fiscalización, pero no brindaba mayores alcances normativos a la autoridad para que ésta pudiera efectuar dicho control de forma adecuada y predecible. ii) La supervisión del empleo

De otro lado, en el ámbito laboral, a través del Decreto Legislativo 140 del 15 de junio de 1981 -Ley de Organización de los Sectores Trabajo y Promoción Social, se determinó el ámbito y conformación de los Sectores Trabajo y Promoción Social; las funciones y estructura orgánica del Ministerio de Trabajo y Promoción Social; y las funciones básicas de los Organismos Públicos Descentralizados pertenecientes a dichos sectores. Destaca de la atención que recibió la fiscalización administrativa en el sector laboral de entonces, la creación de un órgano de línea que, subordinado dentro de la estructura del Ministerio y dependiente del Viceministro de Trabajo, ejercía como función, entre otras, la de vigilar, mediante inspecciones, la aplicación y cumplimiento de las disposiciones laborales, convenios colectivos o contratos individuales de trabajo, así como de las normas técnicas sobre higiene y seguridad ocupacional.

Fue, entonces, la Dirección General de Inspección quien tuvo a su cargo el ejercicio de esta función y el empleo de las técnicas de supervisión para vigilar el cumplimiento de las obligaciones laborales. Esta Dirección estuvo encargada, además, de normar, dirigir, controlar y evaluar la función inspectiva de trabajo a nivel nacional. Como se aprecia, aunque la fiscalización laboral mereció especial atención durante este periodo, esto no significó la creación de una entidad administrativa especializada para llevar a cabo dicha labor. Por el contrario, las funciones inspectivas y normativas en esta materia fueron asignadas a un órgano subordinado a la dirección del Ministerio de Trabajo y Promoción Social y, por tanto, expuesto también al enfoque e interés político de la alta dirección. Si bien la Dirección General de Inspección contaba con facultades normativas, no gozaba de autonomía administrativa ni económica que pudiera fortalecer y garantizar la imparcialidad en el cumplimiento de sus labores.

Destaca de este periodo en materia de supervisión laboral, la aprobación del Decreto Supremo 003-83-TR del 19 de febrero de 1983, a través del cual se dictaron medidas 
referentes a ordenar el desarrollo de la inspección del trabajo y las reglas de su procedimiento, con el objetivo de vigilar el cumplimiento de las disposiciones legales y convencionales de trabajo y de las de higiene y seguridad ocupacional. Esta normativa desarrolló, por un lado, cuestiones referidas a las facultades, obligaciones y prohibiciones de los inspectores de trabajo en el marco de las visitas inspectivas, lo cual brindó garantías a favor de los administrados fiscalizados; y, por el otro, algunas formalidades a ser observadas en el desarrollo y conclusión de la fiscalización, destacando algunas reglas referidas a las actas de inspección, la información que ésta debía contener, los plazos para que sean subsanados los incumplimientos comprobados (según la naturaleza de cada infracción) y su impugnabilidad. Sobre esto último, los supervisados o sus representantes solo podían impugnarla si hubieran dejado constancia en la misma de su disconformidad con lo registrado por el inspector.

De acuerdo a estas reglas de fiscalización laboral, si durante el curso de la inspección surgían cuestiones litigiosas o que exigiesen la actuación de prueba adicional, se ordenaba el corte del procedimiento inspectivo, manteniendo éste su valor probatorio respecto de los hechos ya constatados. Llama la atención que las actas elaboradas por el inspector, en estos casos, constituían instrumentos públicos que "merecían fin" (una suerte de presunción de veracidad), mientras no se probara lo contrario, cuestión que dista, sin lugar a dudas, de su actual regulación en el TUO LPAG, donde constituyen pruebas preconstituidas y no gozan de presunción de veracidad.

A partir de lo advertido durante este período, se aprecia que en el sector laboral existieron normas de fiscalización administrativa que orientaron la operatividad de la misma (disposiciones sobre obligaciones del supervisor, derechos del supervisado, entre otros afines), con lo cual se garantizó su realización sistemática. Conviene destacar que la fiscalización asumió un papel trascendente, toda vez que en relación a los derechos laborales en la Constitución de 1979, se contaba con un amplio contenido, pues cuantitativa y cualitativamente, nos encontrábamos ante la Constitución que mejor había abordado el tema laboral (Toyama, 2001, p. 10). Sin embargo, desde la organización administrativa del Estado peruano, debe advertirse que la inspección laboral estuvo a cargo de un órgano al interior del rector político y normativo de este sector. En este periodo, entonces, no se abordó la necesidad de contar con una organización especializada y con mayor autonomía para desempeñar esta función, cuestión que, al día de hoy, es distinta.

iii) El caso particular de la supervisión del mercado, las industrias estratégicas y los servicios públicos

El principal rasgo distintivo del tratamiento legislativo de la fiscalización administrativa durante este periodo, qué duda cabe, se encontró críticamente marcado por el régimen económico recogido en la Constitución de 1979. La práctica de entonces da cuenta de la existencia de un Estado empresario robusto que, en adición, contaba con el monopolio de las principales actividades e industrias económicas, principalmente de los servicios públicos (Kresalja y Ochoa, 2009, p. 119-122). La alta presencia empresarial del Estado y la reserva de sectores básicos en sus manos amoldaron (o, incluso, negaron) el desarrollo de la actividad de fiscalización administrativa durante este periodo. Por un lado, se aprecia la ausencia de una verdadera fiscalización de la prestación de los servicios públicos, sobre todo por tener el Estado a su cargo la prestación de los mismos. Por el otro, la tutela de la libre competencia, durante un régimen marcado por la participación pública subvencionada en la economía hizo innecesaria (o poco conveniente) la fiscalización del mercado y, mucho menos pertinente, la creación de una autoridad administrativa que asumiera dicha tarea.

Respecto a la prestación de los servicios públicos, se evidenció durante este periodo una presencia absoluta del Estado como gran prestador de los mismos y, del mismo modo, una labor de fiscalización encomendada a órganos subordinados al interior de las autoridades políticas de cada sector. Para empezar, en el caso del sector eléctrico, la Ley 23406 - Ley General de Electricidad, atribuyó la labor fiscalizadora a la Dirección General de Electricidad, órgano técnico normativo de línea del Ministerio de Energía y Minas. Esta Dirección asumió el rol normativo del sector y la tarea de fiscalizar las actividades relativas a la generación, transmisión, interconexión, distribución, comercialización y utilización de la energía eléctrica, así como la función de sancionar a las empresas por incumplimiento de sus obligaciones y responsabilidades, especialmente por deficiencia en la prestación de los servicios. De acuerdo al artículo 116 de la Ley General de Electricidad, la fiscalización de la Dirección General de Electricidad comprendía toda la amplitud de normas de este sector. Así, debía tener en cuenta lo dispuesto en esta ley, su reglamento, el Código Nacional de Electricidad y cualquier otra norma técnica y de procedimientos dictados para tales efectos. 
En este mismo sector, el Reglamento de la Ley General de Electricidad, aprobado por Decreto Supremo 031-82-EM-VM, agregó en su artículo 224 que los funcionarios que ejercían la labor de control y fiscalización debían estar expresamente facultados para el objeto mediante la respectiva credencial que así los identificara ${ }^{(3)}$. Estas labores de fiscalización incluían, además, las de vigilancia en el cumplimiento del cobro de la tarifa eléctrica, conjuntamente coordinado con la Comisión de Tarifas Eléctricas. Finalmente, no se establecían mayores garantías o reglas para la supervisión, seguramente porque los agentes que participaban en esta industria eran básicamente Electroperú y las empresas de servicio público de electricidad pertenecientes o vinculadas a ésta, es decir, se trataba del mismo Estado, respecto del cual, un órgano de línea dentro del ministerio rector (de carácter político) no ejercía plenamente la fiscalización en la práctica.

Una situación similar se advertía en el sector telecomunicaciones. Durante este periodo, la prestación de este servicio se encontró regulada por el Decreto Ley 19020 - Ley General de Telecomunicaciones, publicada en 1971. Lo particular de este régimen es que dejaba "bajo control del Estado" la prestación de estos servicios, atribuyendo al Ministerio de Transportes y Comunicaciones el aseguramiento del mismo. Llama la atención la ausencia de normas que desarrollaran en extenso el ejercicio de la supervisión o fiscalización por parte de esta autoridad administrativa, sobre todo porque sí se recogían disposiciones referidas a la potestad sancionadora a cargo de dicho Ministerio por infracciones a las obligaciones dispuestas en esta industria. Del mismo modo que para el caso de la industria eléctrica, considero que dicha ausencia de normas no es sorpresa si se advierte que la prestación de este servicio público se encontraba reservado en titularidad estatal. La fiscalización, en este periodo, se "amoldó" (al punto de prácticamente desaparecer o emplearse parcializadamente) y se instrumentalizó a favor del Estado empresario. Mención aparte merece la existencia, a partir de 1981, de una Comisión Reguladora de Tarifas de Comunicaciones (rol que ahora cumple OSIPTEL), creada como órgano público descentralizado del Ministerio de Transportes y Comunicaciones, respecto de la cual las normas de este periodo no reconocen mayores funciones de supervisión.

Finalmente, en el ámbito de la prestación del servicio de agua potable y saneamiento, este periodo estuvo también marcado por la posición monopólica del Estado sobre este sector. Destaca la labor del Ministerio de Vivienda y Construcción creado por el Decreto Legislativo 143 en 1981, como ente rector político del sector $y$, sobre todo, de las empresas públicas que asumían las funciones de prestación del servicio de agua potable y saneamiento en el país, destacando entre ellas, sobre todo, el Servicio Nacional de Abastecimiento de Agua Potable y Alcantarillado (SENAPA), el cual, de acuerdo al artículo 28 de esta Ley, era el encargado de ejecutar la política del Estado en el desarrollo, control, operación y mantenimiento de los servicios de agua potable y alcantarillado urbanos a nivel nacional, con funciones específicas para este fin, en los aspectos de planeamiento, programación, financiamiento, normatividad, preparación de proyectos, ejecución de obras, asesoría y asistencia técnica, supervisión de funcionamiento y evaluación de resultados con la facultad de fijar y actualizar tarifas para los servicios que prestaba. EI SENAPA se constituyó como una sociedad integrada a su vez por 15 empresas (entre las cuales destacó SEDAPAL) y asumió las funciones y responsabilidad rectoras, reguladoras y de prestación de los servicios de agua potable y saneamiento; una suerte de fiscalización "endogámica" de la cual no se pueden extraer mayores desarrollos que simplemente la conclusión de que ésta no era imparcial o, en todo caso, se efectuaba de forma aparente.

Por lo demás, el sector de agua potable y saneamiento no contaba con mayores disposiciones sobre las formalidades que debían observarse o los derechos del supervisado, pues, nuevamente, era el mismo Estado el prestador de estos servicios. La presencia pública a nivel empresarial se dio en su totalidad a nivel nacional y no se previeron siquiera normas en materia de fiscalización o supervisión en este sector. Por tanto, la fiscalización (ausente en este caso) no demandó una reforma en la estructura administrativa del Estado peruano. Primaron, más bien, órganos ejecutores de obras, antes que órganos supervisores de la calidad del servicio. La atención pública estaba en la expansión de la infraestructura para brindar el servicio, antes que en la supervisión de su efectiva prestación.

(3) Constitución Política de 1993

Artículo 82.- La Contraloría General de la República es una entidad descentralizada de Derecho Público que goza de autonomía conforme a su ley orgánica. Es el órgano superior del Sistema Nacional de Control. Supervisa la legalidad de la ejecución del Presupuesto del Estado, de las operaciones de la deuda pública y de los actos de las instituciones sujetas a control (...). 
3.3. Conclusión preliminar: una fiscalización negada, aparente o sin garantías subordinada a un Estado empresario y asistencial

Del análisis realizado al marco constitucional y legal aplicable durante este periodo, pueden concluirse dos cuestiones fundamentales. Primero, la fiscalización administrativa se encontró atada a los fines políticos del sector correspondiente, razón por la cual no se requirió el diseño o estructura de entidades especializadas y con mayores niveles de autonomía para el despliegue de esta función. De acuerdo a esto, se advierte que durante este periodo, a excepción de la Autoridad Tributaria, la fiscalización administrativa se ejerció por órganos de línea integrados dentro de los ministerios o entes rectores políticos. Esto no solo suponía limitación a nivel de organización interna y de personal, sino también a nivel de presupuesto. Llama la atención, además, que a mayor presencia de Estado (Estado "robusto", empresario), menor atención y especialización de la fiscalización administrativa.

Segundo, este periodo destacó por no contener mayor desarrollo sobre las garantías, derechos y obligaciones que debían observar tanto los fiscalizadores como los fiscalizados (salvo menciones aisladas) durante una supervisión. Cada normativa en particular se ocupaba de detallar las funciones de supervisión y el objeto de las mismas, pero no comprendían un estatuto claro y garante de principios a favor de los administrados. Esto, claro está, porque quien era "supervisado" en la mayoría de los casos, era el mismo Estado.

\section{El proceso de reforma del} Estado peruano en la década del 90 . El de sarrollo heterogéneo de la fiscalización administrativa destinado a atender los nuevos roles del Estado garante

\subsection{Los nuevos cauces constitucionales que reclaman un fortalecimiento (especialización) de la fiscalización administrativa}

La aprobación de una nueva Constitución en 1993 marcó el inicio de un proceso de reforma estructural en el Perú. Principalmente, el cambio en materia económica exigió un Estado subsidiario, pero también "garante" frente a los nuevos bienes jurídicos y principios que debían tutelarse bajo este nuevo marco fundamental. Para cumplir con este propósito, el Estado debía fortalecer y especializar su potestad fiscalizadora. Si bien la fiscalización administrativa no recibió un desarrollo explícito a nivel constitucional, esta situación no significó un desconocimiento absoluto de la misma. De hecho, a lo largo de este texto fundamental pueden advertirse diversas disposiciones con alusiones o referencias a ella (Tirado, 2011). Además, esta parquedad sobre la fiscalización presente en la Constitución de 1993 ha sido complementada en extenso por importante jurisprudencia del Tribunal Constitucional, la que a su vez se ha preocupado por determinar sus contornos y límites.

El gran tránsito del Estado prestador (desinteresado en fiscalizarse a sí mismo), a uno garante (Esteve, 2007), obligado a fiscalizar a los nuevos agentes del mercado y a la sociedad, exige el desarrollo y especialización de una potestad de fiscalización para velar por que los privados, quienes ahora prestarán servicios públicos y esenciales de manera directa, lo hagan en estricto cumplimiento del ordenamiento, pero adicionalmente a lo económico, esta necesidad está complementada con el rol directo que asume el Estado a nivel constitucional para la tutela y satisfacción de los derechos fundamentales. Para el cumplimiento de este marco, el Estado debía transformar su organización administrativa y amoldarla a sus nuevos retos.

Ahora bien, la Constitución de 1993 emplea indistintamente y como sinónimos los términos "fiscalización" y "supervisión" para aludir a algunas de las competencias que este texto normativo reconoce a determinados organismos. Son usadas muchas veces, por un lado, para denotar aquel control que realiza el Estado con respecto al ejercicio de sus propias funciones, siendo un ejemplo el artículo $82^{(4)}$ referido a las funciones de la Contraloría General de la República, al cual se encarga la supervisión de la legalidad de la ejecución del presupuesto del Estado, de las operaciones de la deuda pública y de los actos de las instituciones sujetas a control. Del mismo modo, en el caso de la Defensoría del Pueblo ${ }^{(5)}$, el artículo 162 de la Constitución

(4) Constitución Política de 1993

Artículo 162.- Corresponde a la Defensoría del Pueblo defender los derechos constitucionales y fundamentales de la persona y de la comunidad; y supervisar el cumplimiento de los deberes de la administración estatal y la prestación de los servicios públicos a la ciudadanía.

(5) Constitución Política de 1993

Artículo 16.- Tanto el sistema como el régimen educativo son descentralizados. 
le reconoce a este organismo la supervisión del cumplimiento de los deberes de la administración estatal y la prestación de los servicios públicos a la ciudadanía. Sin embargo, el empleo de la noción de fiscalización en la Constitución no se limita únicamente a la labor de control y supervisión entre organismos integrantes del aparato estatal, sino también se extiende a la vigilancia en la atención de los derechos fundamentales de las personas (Tirado, 2011, p. 252), como en el caso del derecho a la educación, a la inviolabilidad del domicilio, a la inviolabilidad de las comunicaciones y documentos privados $y$, adicionalmente, con respecto a mandatos que la propia Constitución otorga al Estado en materias como la de protección al consumidor.

Respecto al derecho a la educación, la Constitución prevé que el Estado supervisa su cumplimiento y la calidad de la misma ${ }^{(6)}$. Este mandato constitucional justifica actualmente la existencia de la Superintendencia Nacional de Educación Universitaria, que desde su creación mediante la Ley 30220 - Ley Universitaria, cumple dicha labor fiscalizadora y ha sido objeto de reconocimiento en su labor con ocasión del Caso "Ley Universitaria" resuelto por el Tribunal Constitucional. En dicha ocasión, el Tribunal Constitucional sostuvo que la educación era un derecho fundamental, pero también un servicio público, en la medida que se trataba de una prestación pública que explicita una de las funciones-fines del Estado, de ejecución per se o por terceros bajo fiscalización estatal (FJ 20 STC Caso "Ley Universitaria")(7). Asimismo, cuando el Estado abre la posibilidad de que determinadas actividades, en principio a él encomendadas, sean llevadas a cabo por particulares, genera con ello un deber especial de vigilancia y fiscalización del servicio brindado, ya que su cumplimiento no es solo una cuestión concerniente a la entidad privada, sino que guarda especial relación con los fines del propio Estado (FJ 31 STC Caso Ley Universitaria). De ahí nuevamente, que la fiscalización ocupe un lugar primordial en la concreción del derecho a la educación.

Por otro lado, la Constitución hace referencia a la fiscalización con ocasión del derecho a la inviolabilidad del domicilio, señalando como excepción a dicho derecho el que se pueda realizar investigaciones 0 registros sin autorización de la persona que habita el domicilio o sin mandato judicial por motivo de sanidad o de grave riesgo, motivos que deben ser regulados por Ley ${ }^{(8)}$. Es decir, se prevé constitucionalmente alguna de las

El Estado coordina la política educativa. Formula los lineamientos generales de los planes de estudios así como los requisitos mínimos de la organización de los centros educativos. Supervisa su cumplimiento y la calidad de la educación.

(6) Sentencia del 10 de noviembre de 2015. Expedientes 0014-2014-P1/TC, 0016-2014-PI/TC, 0019-2014-P1/TC y 0007-2015-PI/TC

(7) Constitución Política de 1993

Artículo 2.- Toda persona tiene derecho:

(...)

9. A la inviolabilidad del domicilio. Nadie puede ingresar en él ni efectuar investigaciones o registros sin autorización de la persona que lo habita o sin mandato judicial, salvo flagrante delito o muy grave peligro de su perpetración. Las excepciones por motivos de sanidad o de grave riesgo son reguladas por la ley.

(8) En la Sentencia del Tribunal Constitucional recaída en el Expediente 02389-2009-PA, esta instancia señaló:

(...)

10. En este orden de ideas, puede afirmarse que el término domicilio comprende aquel espacio específico elegido por el ocupante para que pueda desarrollar libremente su vida privada o familiar, es decir, es un espacio-ámbito de intimidad del que él, y sólo él, dispone. $Y$ es que el rasgo esencial que define el domicilio en sentido constitucional reside en la aptitud para desarrollar en él vida privada y en su destino específico a tal desarrollo aunque sea eventual.

Por dicha razón, resulta válido afirmar que el objeto del derecho a la inviolabilidad del domicilio es proteger un espacio físico inmune a la penetración de cualquiera sin el consentimiento de su titular, por ser un espacio privado. De este modo, el domicilio inviolable es un espacio que la propia persona elige para desarrollarse, sin estar sujeto necesariamente a los usos y convenciones sociales y ejerce su libertad más íntima, así como su intimidad o privacidad.

Teniendo presente ello, puede señalarse de modo ilustrativo que la celda de un centro penitenciario no puede ser considerada como domicilio, debido a que dicho espacio físico no ha sido objeto de libre elección por su ocupante y porque el ingreso a un centro penitenciario supone la inserción en un ámbito de intenso control público.

11. De ahí que el domicilio protegido por el inciso 9) del artículo 2 de la Constitución se caracterice por ser un espacio específico que es elegido libremente por su ocupante y que excluye las intervenciones, invasiones o injerencias arbitrarias o ilegales de los particulares y de la autoridad pública, incluidas las que puedan realizarse sin penetración directa por medio de aparatos mecánicos, electrónicos u otros análogos.

Ello porque la expresión "domicilio" tiene más amplitud en la Constitución que en la legislación civil, pues protege, entre otros, el recinto o vivienda, sea móvil o inmóvil, de uso permanente, transitorio o accidental; así como todos aquellos espacios cerrados en donde las personas desarrollan su intimidad y personalidad separada de los terceros y sin su presencia, como por ejemplo la habitación de un hotel, el camarote de un barco, los bungaló de un club, etc.

Dicho de otro modo, la noción constitucional de domicilio no puede equipararse al concepto tradicional que utiliza el derecho privado, en el que se le concibe como punto de localización o centro de imputación de derechos y obligaciones. La noción constitucional de 
acciones materiales de cómo el Estado despliega la potestad de fiscalización, como es el realizar investigaciones o registros, con el detalle de que ello sea sin autorización por parte de la persona que habita en el domicilio(9).

Muy relacionado al derecho a la inviolabilidad del domicilio se encuentra el derecho a la intimidad, el cual constituye para el Tribunal Constitucional un límite a la actuación de la potestad fiscalizadora de la Administración Pública. En estos casos, los requerimientos por parte de ésta deben ser especialmente motivados, así en un caso de fiscalización tributaria, el Tribunal Constitucional señaló que:

“14. (...) En efecto, si bien la Administración goza de las atribuciones fiscalizadoras anotadas, ello no implica que no tenga que motivar adecuadamente sus requerimientos, más aún cuando la información requerida no determina por sí misma una finalidad de relevancia tributaria evidente. Se pone de manifiesto entonces que la Administración no ha cumplido con sustentar adecuadamente tal requerimiento, por lo que, al no contarse con la fundamentación pertinente, tal solicitud deviene en arbitraria, afectándose con ello, sí, el derecho a la intimidad (...)"(10).
En tal razón, el deber de motivación vendría a ser una garantía frente a la actividad de fiscalización frente a aquellas investigaciones que pueden amenazar el derecho a la intimidad. En estos casos, si bien la potestad de fiscalización se manifestará a través de actos materiales, estos no podrán efectuarse de forma arbitraria.

Por otro lado, se encuentran también referencias a la potestad de fiscalización en la Constitución en relación al derecho fundamental al secreto y a la inviolabilidad de las comunicaciones y documentos privados, pues se contempla que los libros, comprobantes y documentos contables y administrativos estarán sujetos a inspección por parte de la autoridad competente y, de nuevo, conforme lo disponga la Ley ${ }^{(11)}$. Mientras que, con respecto al régimen tributario de Centros de Educación(12), se indica que por

domicilio protege cualquier ámbito en el que la persona pueda desarrollar su vida privada, en su doble faceta de lugar en el que pueda desarrollar libremente cierta actividad y del que se excluye la entrada y el conocimiento ajeno.

(9) En la Sentencia del Tribunal Constitucional recaída en el Expediente 02389-2009-PA, esta instancia señaló:

(...)

10. En este orden de ideas, puede afirmarse que el término domicilio comprende aquel espacio específico elegido por el ocupante para que pueda desarrollar libremente su vida privada o familiar, es decir, es un espacio-ámbito de intimidad del que él, y sólo él, dispone. Y es que el rasgo esencial que define el domicilio en sentido constitucional reside en la aptitud para desarrollar en él vida privada y en su destino específico a tal desarrollo aunque sea eventual.

Por dicha razón, resulta válido afirmar que el objeto del derecho a la inviolabilidad del domicilio es proteger un espacio físico inmune a la penetración de cualquiera sin el consentimiento de su titular, por ser un espacio privado. De este modo, el domicilio inviolable es un espacio que la propia persona elige para desarrollarse, sin estar sujeto necesariamente a los usos y convenciones sociales y ejerce su libertad más íntima, así como su intimidad o privacidad.

Teniendo presente ello, puede señalarse de modo ilustrativo que la celda de un centro penitenciario no puede ser considerada como domicilio, debido a que dicho espacio físico no ha sido objeto de libre elección por su ocupante y porque el ingreso a un centro penitenciario supone la inserción en un ámbito de intenso control público.

11. De ahí que el domicilio protegido por el inciso 9) del artículo 2 de la Constitución se caracterice por ser un espacio específico que es elegido libremente por su ocupante y que excluye las intervenciones, invasiones o injerencias arbitrarias o ilegales de los particulares y de la autoridad pública, incluidas las que puedan realizarse sin penetración directa por medio de aparatos mecánicos electrónicos u otros análogos.

Ello porque la expresión "domicilio" tiene más amplitud en la Constitución que en la legislación civil, pues protege, entre otros, el recinto o vivienda, sea móvil o inmóvil, de uso permanente, transitorio o accidental; así como todos aquellos espacios cerrados en donde las personas desarrollan su intimidad y personalidad separada de los terceros y sin su presencia, como por ejemplo la habitación de un hotel, el camarote de un barco, los bungaló de un club, etc.

Dicho de otro modo, la noción constitucional de domicilio no puede equipararse al concepto tradicional que utiliza el derecho privado, en el que se le concibe como punto de localización o centro de imputación de derechos y obligaciones. La noción constitucional de domicilio protege cualquier ámbito en el que la persona pueda desarrollar su vida privada, en su doble faceta de lugar en el que pueda desarrollar libremente cierta actividad y del que se excluye la entrada y el conocimiento ajeno.

(10) STC Expediente 04168-2006-PA

(11) Constitución Política de 1993

Artículo 2.- Toda persona tiene derecho:

(...)

10. Al secreto y a la inviolabilidad de sus comunicaciones y documentos privados. (...)

Los libros, comprobantes y documentos contables y administrativos están sujetos a inspección o fiscalización de la autoridad competente, de conformidad con la ley. Las acciones que al respecto se tomen no pueden incluir su sustracción o incautación, salvo por orden judicial.

(12) Constitución Política de 1993

Artículo 19.- (...) La ley establece los mecanismos de fiscalización a que se sujetan las mencionadas instituciones, así como los requisitos y condiciones que deben cumplir los centros culturales que por excepción puedan gozar de los mismos beneficios. 
Ley se establecen los mecanismos de fiscalización a que se sujetan las universidades, institutos superiores y demás centros educativos constituidos conforme a la legislación, así como los requisitos y condiciones que deben cumplir los centros culturales que por excepción puedan gozar de los mismos beneficios tributarios.

Asimismo, con ocasión del mandato de protección de los consumidores y usuarios contenido en el artículo $65^{(13)}$ de la Constitución, esta disposición lleva implícita la potestad de fiscalización al señalar que el Estado vela, en particular, por la salud y la seguridad de la población. Esto, sin duda, supone el reconocimiento de algunas atribuciones necesarias para lograr ello, entre las cuales destacará la supervisión administrativa. Esta postura ha sido sostenida del mismo modo por el Tribunal Constitucional:

\begin{abstract}
"13. Por ello, a juicio del Tribunal Constitucional, la primera parte del artículo 65 de la Constitución contiene un genérico deber especial de protección del consumidor y usuario que asume el Estado, cuyas formas como puede concretizarse, se traducen, sólo de manera enunciativa en garantizar "el derecho a la información sobre los bienes y servicios que se encuentran a su disposición en el mercado", así como en velar, "en particular, por la salud y la seguridad de la población".

Estas concretizaciones del deber especial de protección sobre los derechos e intereses de los consumidores y usuarios no se agotan allí, puesto que incluyen la expedición de directivas, el establecimiento de procedimientos administrativos, la aplicación de las leyes y reglamentos de conformidad con los derechos fundamentales, entre muchos otros factores a tomarse en consideración ${ }^{(14)}$.
\end{abstract}

Finalmente, cabe mencionar que la fiscalización ha sido también referida a través de las recientes reformas constitucionales, en específico, la realizada a través de la Ley 30905, Ley que modifica el artículo 35(15) de la Constitución Política del Perú para regular el financiamiento de las organizaciones políticas. Se ha previsto en el nuevo texto constitucional de dicho artículo que, por ley, deban establecerse las disposiciones orientadas a asegurar la transparencia sobre el origen de los recursos de las organizaciones políticas, así como su correspondiente verificación, fiscalización, control y sanción.

Por lo tanto, aunque de forma indirecta, la fiscalización administrativa ha merecido atención constitucional suficiente para consagrar la necesidad e importancia de la misma en el logro de los cometidos públicos. Es a partir de ella y del encuadre de un nuevo Estado, que la fiscalización administrativa recibió un desarrollo legislativo particular, aunque heterogéneo, dependiendo del sector o materia que era objeto de tutela. Este tratamiento singular, diferenciado o disperso se hizo presente al mismo tiempo que se creaban organismos administrativos especializados para el ejercicio de esta actividad. Los acápites que a continuación desarrollo dan cuenta de la evolución de la fiscalización administrativa a partir de la regulación del mercado, la tutela de la libre competencia y la procura y defensa de derechos constitucionales (sobre todo, de carácter social o prestacional), pero también de diversos regímenes legales con reglas, calificaciones, principios y pautas muy disímiles entre ellos.

\subsection{Fiscalización administrativa, especialización y tecnicidad: el surgimiento de los organismos reguladores}

Habiéndose dispuesto una necesaria contracción de la participación del Estado en la economía, éste inició un proceso de transformación y reorganización, lo que lo llevó a desmonopolizar, liberalizar el mercado, y transferir a manos privadas la gestión y operación de los servicios públicos. Esto último tuvo lugar tanto mediante la venta de las empresas estatales, como a través del empleo de técnicas de habilitación (principalmente, mediante concesiones) a favor del sector privado. De esta forma, se evidenció un vuelco en los modos de concreción del fin público: el Estado es ahora el promotor de las condiciones para el ejercicio de las libertades económicas, el principal creador de riqueza es el mercado y la posición del Estado ya no le reconoce a éste una reserva de actividades, ni siquiera en aquellos ámbitos calificados como servicios públicos. Ahora los privados asumen la

(13) Constitución Política de 1993

Artículo 65.- El Estado defiende el interés de los consumidores y usuarios. Para tal efecto garantiza el derecho a la información sobre los bienes y servicios que se encuentran a su disposición en el mercado. Asimismo vela, en particular, por la salud y la seguridad de la población.

(14) STC Expediente 0858-2003-AA/TC

(15) Organizaciones Políticas

"Artículo 35.- (...) Mediante ley se establecen disposiciones orientadas a asegurar el funcionamiento democrático de las organizaciones políticas y la transparencia sobre el origen de sus recursos económicos, así como su verificación, fiscalización, control y sanción. 
prestación de estos servicios, pero bajo una supervisión especializada por parte del Estado, quien para este propósito crea a los organismos reguladores (Danós, 2004, p. 417-418; Tassano, 2010, p. 369-374; Maldonado, 2016, p. 10) como nuevo criterio de organización administrativa al interior del Poder Ejecutivo.

Los organismos reguladores creados con ocasión de esta reforma del Estado fueron el Organismo Supervisor de la Inversión Privada en Telecomunicaciones (OSIPTEL); el Organismo Supervisor de la Inversión en Energía (actual OSINERGMIN); el Organismo Supervisor de la Inversión en Infraestructura de Transporte de Uso Público (OSITRAN); y, la Superintendencia Nacional de Servicios de Saneamiento (SUNASS). Estos reguladores asumieron una nueva función en esta evolución del Estado, pero sobre todo se les reclamó especialización y autonomía. Por ello, un rasgo característico a todos ellos fue contar con personería jurídica pública propia (dejándose de lado la creación de órganos al interior de los entes rectores políticos) y el encontrarse adscritos a la Presidencia del Consejo de Ministros, como opción para no supeditar al regulador a la dirección política de un sector o cartera ministerial específica. A esto se le sumó, desde luego, el gozar de autonomía administrativa, normativa y económica.

Si bien cada organismo regulador cuenta con su propia ley de creación y marcos normativos correspondientes, destaca en el ordenamiento la Ley 27332 - Ley Marco de los Organismos Reguladores de la Inversión Privada en los Servicios Públicos, la cual identifica a los organismos que gozan de esta condición en el Perú y lista las funciones que estos ejercen dentro de sus respectivos ámbitos de competencia, las mismas que son ejercidas de acuerdo a los alcances y limitaciones establecidos en sus respectivas leyes y reglamentos de creación. La Ley 27332 reconoció como funciones generales de los organismos reguladores la función reguladora, normativa, sancionadora, de solución de controversias, de solución de reclamos de usuarios y, de mayor relevancia para este estudio, supervisora. Esta última comprendía, precisamente, "la facultad de verificar el cumplimiento de las obligaciones legales, contractuales o técnicas por parte de las entidades o actividades supervisadas, así como la facultad de verificar el cumplimiento de cualquier mandato o resolución emitida por el organismo regulador o de cualquier otra obligación que se encuentre a cargo de la entidad o actividad supervisada"(16).

Esta nueva y fortalecida función supervisora se operativizó a partir del diseño de cada uno de los organismos reguladores, se especializó de acuerdo al servicio o materia objeto de control y se desarrolló heterogéneamente en función al marco normativo de cada uno, de acuerdo al detalle que desarrollo seguidamente.

i) Superintendencia Nacional de Servicios de Saneamiento (SUNASS)

Mediante Decreto Ley 25965 del 19 de diciembre de 1992, se creóla Superintendencia Nacional de Servicios de Saneamiento (SUNASS). Esta entidad tiene asignada la función de normar, regular, supervisar y fiscalizar la prestación de los servicios de saneamiento, cautelando de forma imparcial y objetiva los intereses del Estado, de los inversionistas y del usuario. Es preciso indicar que los servicios de saneamiento comprenden la prestación regular de los servicios de agua potable, alcantarillado sanitario, tratamiento de aguas residuales para disposición final o reúso, y disposición sanitaria de excretas, en los ámbitos urbano y rural, conforme al Decreto Legislativo 1280 (Ley Marco de la Gestión y Prestación de los Servicios de Saneamiento).

Desde su creación, la función supervisora por parte de la SUNASS estuvo sujeta a distintos reglamentos, cada uno de ellos con reglas y disposiciones específicas únicamente aplicables a las labores de fiscalización llevadas a cabo por este regulador. La función normativa reconocida a estos agentes llevó a que estos aprobaran sus propias reglas y garantías al ejercer este poder. Así, el empleo de esta función ha debido observar las reglas contenidas, entre otros, en el "Reglamento de Supervisión y Fiscalización de la Prestación de Servicios de Saneamiento", aprobado mediante Resolución de Consejo Directivo 015-2004-SUNASS-CD; posteriormente, por aquellas dispuestas en el "Reglamento General de Supervisión, Fiscalización y Sanción de las empresas prestadoras de servicios de saneamiento (EPS)", aprobado por la Resolución de Consejo Directivo 003-2007-SUNASS-CD; y finalmente, luego

(16) Se advierte que el legislador distingue entre una función "de supervisión" y otra función denominada "de fiscalización y sanción". Definitivamente, no es conceptualmente correcto formular distinción alguna entre la "supervisión" y la "fiscalización", razón por la cual no es comprensible dicha distinción y tampoco que la fiscalización la hayan equiparado o englobado dentro de la potestad punitiva. 
de las modificaciones introducidas por el Decreto Legislativo 1272, a la reforma aprobada mediante la Resolución de Consejo Directivo 021-2018-SUNASS-CD.

ii) Organismo Supervisor de la Inversión en Energía y Minería (OSINERGMIN)

Por medio de la Ley 26734 del 31 de diciembre de 1996, se creó el Organismo Supervisor de la Inversión en Energía (OSINERG), como un organismo fiscalizador de las actividades que desarrollaban las empresas en los subsectores de electricidad e hidrocarburos, siendo parte integrante, en ese entonces, del Sistema Supervisor de la Inversión en Energía compuesto, además, por la Comisión de Tarifas Eléctricas y el Instituto de Defensa de la Competencia y de la Propiedad Intelectual. Posteriormente, mediante la Ley 27332 se dispuso que la Comisión de Tarifas Eléctricas y el OSINERG se integraran como un solo organismo regulador; y, por Ley 28964 - Ley que transfiere competencias de supervisión y fiscalización de las actividades mineras al OSINERG, se incorporó a su competencia la supervisión en el rubro minero. Siendo así, el actualmente OSINERGMIN tiene bajo su competencia la supervisión en los subsectores de electricidad, hidrocarburos y minería (sobre el desarrollo de la industria a cargo de la supervisión por el OSINERGMIN puede verse Dammert, 2010).

Al igual que los demás reguladores, y como expresión de la dispersión o heterogeneidad normativa en esta materia, la función supervisora por parte de OSINERGMIN ha estado sujeta a diversas reglas o marcos reglamentarios propios. Destacan, en ese orden, el "Reglamento de Fiscalización de las Actividades Energéticas", aprobado mediante Decreto Supremo 029-97-EM; el "Reglamento de Supervisión de Actividades Energéticas", aprobado por Resolución de Consejo Directivo 013-2004-OS/CD; el "Reglamento de Supervisión de Actividades Energéticas y Mineras", aprobado por Resolución de Consejo Directivo 324-2007-OS/CD; el Reglamento de Supervisión de Actividades Energéticas y Mineras, aprobado por Resolución de Consejo Directivo 05-2009-OS-CD; el "Reglamento de Supervisión y Fiscalización de las Actividades Energéticas y Mineras de OSINERGMIN", aprobado por Resolución de Consejo Directivo 171-2013-OS-CD; y, finalmente el "Reglamento de Supervisión, Fiscalización y Sanción de las Actividades Energéticas y Mineras a cargo de OSINERGMIN", aprobado por Resolución de Consejo Directivo del Organismo Supervisor de la Inversión en Energía y Minería 040-2017-OS-CD (ajustándose a las modificaciones introducidas por el Decreto Legislativo 1272).

La tecnicidad y complejidad del sector a su cargo, lleva a OSINERGMIN a ejercer sus funciones de supervisión en materias del subsector eléctrico (generación, transmisión, distribución y comercialización de electricidad, planificación, programación y despacho económico del Sistema Eléctrico Interconectado Nacional); del subsector hidrocarburos (exploración, explotación y producción, procesamiento, almacenamiento, transporte, distribución y comercialización); y, del subsector hidrocarburos líquidos (exploración, explotación y producción, procesamiento y refinación, almacenamiento, transporte, distribución y comercialización y otras legalmente atribuidas). Finalmente en las actividades del subsector minero, OSINERGMIN ejerce sus funciones de supervisión de las obligaciones legales y técnicas de seguridad de la infraestructura, las instalaciones y la gestión de seguridad de sus operaciones, en actividades mineras de exploración, explotación, beneficio, transporte minero y almacenamiento de concentrado de mineral.

iii) Organismo Supervisor de la Inversión Privada en Telecomunicaciones (OSIPTEL)

El Decreto Legislativo 702, publicado el 8 de noviembre de 1991, creó el Organismo Supervisor de la Inversión en Telecomunicaciones - OSIPTEL, como encargado de regular el comportamiento de las empresas operadoras, así como las relaciones de dichas empresas entre sí, de garantizar la calidad y eficiencias del servicio brindado al usuario y de regular el equilibrio de las tarifas (Thornberry, 2008, p. 36-38; Zegarra, 2008, p. 132-133; Tovar, 2006, p. 64-93). EI OSIPTEL se constituyó como el organismo que tenía por objetivo general, regular, normar, supervisar y fiscalizar, dentro del ámbito de su competencia, el desenvolvimiento del mercado de servicios públicos de telecomunicaciones y el comportamiento de las empresas operadoras, las relaciones de dichas empresas entre sí, y las de éstas con los usuarios. Se buscaba primordialmente garantizar la calidad y eficiencia del servicio brindado al usuario, para lo cual habría que regular el equilibrio de las tarifas y facilitar al mercado una explotación y uso eficiente de los servicios públicos de telecomunicaciones.

En cuanto a las normas que han regido el ejercicio de la supervisión por parte de este regulador, del mismo modo que en los casos anteriores, se advirtió una gran dispersión de regímenes. De hecho, era común contar 
con regímenes de supervisión puntuales dependiendo del objeto materia de supervisión dentro del amplio universo de servicios de telecomunicaciones. Solo por mencionar algunos, destacaron durante este periodo el "Procedimiento de Supervisión y Control de la Calidad del Servicio", aprobado mediante Resolución del Consejo Directivo 006-CD/95; el "Procedimiento para la Supervisión y Control del Indicador Tiempo de Espera para la Conexión (TEC)", aprobado por Resolución 050-98-PD-OSIPTEL; el "Procedimiento de Supervisión y Control de la Calidad del Servicio Público de Telefonía Móvil", aprobado mediante Resolución de Consejo Directivo 041-99-CD-OSIPTEL; el "Reglamento de Calidad de los Servicios Públicos de Telecomunicaciones", aprobado por Resolución de Consejo Directivo 040-2005-CD-OSIPTEL; el "Procedimiento de Supervisión de los Indicadores de Calidad", aprobado mediante Resolución de Consejo Directivo 029-2009-CD-OSIPTEL; y, el "Reglamento General de Calidad de los Servicios Públicos de Telecomunicaciones", aprobado por Resolución de Consejo Directivo 123-2014-CD-OSIPTEL.

iv) Organismo Supervisor de la Inversión en Infraestructura de Transporte de Uso Público (OSITRAN)

El Organismo Supervisor de la Inversión en Infraestructura de Transporte de Uso Público (OSITRAN) fue creado por la Ley 26917 -Ley de Supervisión de la Inversión Privada en Infraestructura de Transporte de Uso Público y Promoción de los Servicios de Transporte Aéreo, publicada el 23 de enero de 1998. EI OSITRAN tiene la misión de regular el comportamiento de los mercados en los que actúan las Entidades Prestadoras, así como, el cumplimiento de los contratos de concesión, cautelando en forma imparcial y objetiva los intereses del Estado, de los inversionistas y de los usuarios, a fin de garantizar la eficiencia en la explotación de la infraestructura bajo su ámbito.

De esta forma, OSITRAN regula y supervisa los mercados en los que actúan las entidades prestadoras a su cargo, que vienen a ser las empresas públicas y privadas que realizan actividades de explotación de la infraestructura de transporte de uso público. Su ámbito de competencia excluye la provisión de servicios de transporte, por ejemplo, el transporte público. La infraestructura de transporte de uso público bajo su competencia está conformada por la infraestructura aeroportuaria, portuaria, férrea, la red vial nacional y regional y otras infraestructuras públicas de transporte (Tassano, 2008, p. 104).

La actividad de fiscalización del OSITRAN se detalla actualmente en la Resolución de Consejo Directivo 009-2018-CD-OSITRAN, Reglamento de Incentivos, Infracciones y Sanciones del OSITRAN. Este dispositivo indica que este organismo regulador tiene como funciones, entre otras, supervisar y fiscalizar el cumplimiento de las obligaciones asumidas por las Entidades Prestadoras en virtud al correspondiente contrato de concesión o la Normativa Aplicable en materia de infraestructura nacional de transporte de uso público y de prestación de servicios públicos de transporte ferroviario de pasajeros en las vías que forman parte del Sistema Eléctrico de Transporte Masivo de Lima y Callao, que se encuentra bajo su ámbito de competencia. En cuanto a los marcos normativos que han dirigido el ejercicio de la función supervisora por parte de este organismo regulador, pueden mencionarse el "Reglamento General de Supervisión", aprobado por la Resolución de Consejo Directivo 007-99-CD-OSITRAN; el "Reglamento General de Supervisión", aprobado por Resolución de Consejo Directivo 036-2004-CD-OSITRAN; y, el "Reglamento General de Supervisión de OSITRAN", aprobado por Resolución de Consejo Directivo 024-2011-CD-OSITRAN.

Del recuento anterior es posible evidenciar que la desmonopolización de los servicios públicos a cargo del Estado y la participación privada en la prestación de los mismos (todo inmerso dentro de un nuevo régimen económico que exigía un Estado subsidiario) derivó en una reinvención en la organización administrativa. Se requirió precisamente de nuevos organismos que aseguraran especialización y autonomía en la importante labor de supervisar la adecuada prestación de estos servicios. No obstante, las disposiciones y reglas a observar para el desempeño de dicha función se mantuvieron dispersas entre numerosos marcos normativos (reglamentos), muchos de los cuales únicamente resultaban aplicables a obligaciones particulares dentro de las muchas existentes dentro de los sectores correspondientes.

4.3. Liberalización y competencia: la fiscalización del mercado por el INDECOPI Del mismo modo como ahora el Estado peruano concesionaba la prestación de los servicios públicos a los privados, también reconocía a nivel constitucional el principio de libre competencia (artículo 61 de la Constitución). Si bajo la vigencia de la Constitución de 1979, este principio se encontró fácticamente ausente, ahora la libre iniciativa privada (artículo 58 de 
la Constitución) tenía la labor de construir un fenómeno competitivo en el mercado. Para tutelar este bien jurídico, el Estado debía asumir labores especiales de fiscalización y velar porque la libre competencia no se vea transgredida. Este fue el contexto que derivó en la creación del Instituto Nacional de Defensa de la Competencia y de la Protección de la Propiedad Intelectual (INDECOPI) mediante Decreto Ley 25868, publicado el 24 de noviembre de 1992.

EI INDECOPI es el organismo encargado de la aplicación de las normas legales destinadas a proteger el mercado de las prácticas monopólicas que resultaran controlistas y restrictivas de la competencia en la producción y comercialización de bienes y en la prestación de servicios, así como de las prácticas que generaran competencia desleal, y de aquellas que afectaran a los agentes del mercado y a los consumidores; pero también para la tutela de los derechos de propiedad intelectual en todas sus manifestaciones, la calidad de los productos, la defensa de los consumidores, el proceso del comercio exterior, y la protección del crédito mediante la conducción al sistema concursal. Actualmente, su organización y funciones se encuentran previstos en el Decreto Legislativo 1033. Aunque inicialmente se encontró adscrito a una cartera ministerial específica (el, entonces, Ministerio de Industria, Turismo, Integración y Negociaciones Comerciales Internacionales), actualmente responde a la Presidencia del Consejo de Ministros.

Desde luego, para el cumplimiento de sus funciones, el INDECOPI ejerce funciones fiscalizadoras y sancionadoras. Respecto a las primeras, y en lo que se refiere a la supervisión de la libre competencia, destaca la labor realizada por sus comisiones (entre ellas, la Comisión de Eliminación de Barreras Burocráticas, la Comisión de Defensa de la Libre Competencia, la Comisión de Fiscalización de la Competencia Desleal, a través de las secretarías técnicas, y la Comisión de Protección al Consumidor), sin dejar de lado que, a partir de 2012, se creó como órgano de línea del INDECOPI a la Gerencia de Supervisión y Fiscalización, la cual formula y propone normas de política de alcance nacional sobre prevención, a través de actividades de supervisión y la fiscalización del cumplimiento de obligaciones legales y contractuales. Este órgano, además, por encargo de los órganos resolutivos y secretarías técnicas, puede prestar el apoyo técnico-legal y de ejecución, en el ejercicio de las facultades de supervisión y fiscalización en las actividades económicas que éstos determinen (aunque por su nivel de complejidad, algunas son realizadas directamente por las secretarías de las comisiones correspondientes).

Por la especialidad del bien jurídico tutelado por parte del INDECOPI, sobre todo en lo referido a la libre competencia, ha sido este sector el que ha evidenciado un destacado avance en la implementación de prácticas que han amoldado la fiscalización administrativa a los retos que el mercado y la tecnología le ponen en frente. Así pues, ante la dificultad de advertir superficialmente prácticas anticompetitivas, se han empezado a emplear otros mecanismos complementarios, entre los que destacan los programas de cumplimiento, recompensa y clemencia. La fiscalización en este ámbito no parece ser cuestión de exclusiva iniciativa del poder público, sino que requiere del empleo de incentivos a favor del sector privado por medio de técnicas colaborativas que involucre también a este último en la supervisión del cumplimiento.

\subsection{Derechos sociales y programáticos y su incidencia en el alcance y empleo de la fiscalización.}

Superado el contexto que a nivel económico había exigido una transformación administrativa del Estado peruano, mayormente abocada a reducir su participación empresarial, velar por el libre mercado y garantizar la prestación de servicios públicos, los años siguientes han dado cuenta de un desarrollo de la fiscalización administrativa, pero esta vez dirigida al fortalecimiento (especialización) de las labores del Estado para supervisar y tutelar bienes jurídicos difusos y derechos sociales. No solo ello, sino que este desarrollo ha tenido lugar por medio de la creación de organismos administrativos especializados y dedicados principalmente a dicha función. En este apartado doy cuenta de algunos de ellos.

i) La tutela del medio ambiente a cargo del OEFA

En el sector ambiental, la intervención del Estado se encuentra justificada por las externalidades generadas como consecuencia de la actividad económica humana en el ambiente (OEFA, 2014, p. 376); sin embargo, hasta antes de 2008, la gestión ambiental en el país y la estructura organizacional para ese fin presentaban serias limitaciones. Así la dispersión y escasa integración y coordinación estructural y normativa constituían factores que dificultaban respuestas efectivas a los desafíos ambientales.

En este contexto, a través de la Segunda Disposición Complementaria Final del Decreto Legislativo 1013 -Ley de Creación, Organización y Funciones del Ministerio del Ambiente, de 2008 fue creado el Organismo 
de Evaluación y Fiscalización Ambiental (OEFA) como un organismo público técnico especializado, adscrito a dicho Ministerio y encargado de la fiscalización, la supervisión, el control y la sanción en materia ambiental. Las funciones asignadas al OEFA fueron asumidas de forma progresiva, y para su fortalecimiento y consolidación como entidad rectora del Sistema Nacional de Evaluación y Fiscalización Ambiental (SINEFA), tuvieron que emitirse una serie de normas que precisaron el alcance de sus funciones y fijaron detalladamente su labor operativa (Aldana, 2013, p. 331).

Para fortalecer la supervisión en materia ambiental, se han aprobado a la fecha distintos marcos normativos, entre ellos la Ley 29325 - Ley del Sistema Nacional de Evaluación y Fiscalización Ambiental, con la finalidad de asegurar el cumplimiento de la legislación ambiental por parte de todas las personas naturales o jurídicas, así como supervisar y garantizar que las funciones de evaluación, supervisión, fiscalización, control y la potestad sancionadora en materia ambiental se realicen de forma independiente, imparcial, ágil y eficiente. Posteriormente, la Ley 30011 aprobó un nuevo enfoque de la fiscalización ambiental, que significó el fortalecimiento de la fiscalización ambiental no solo a partir de la imposición de sanciones disuasivas, sino también otorgando a los administrados la oportunidad de subsanar incumplimientos leves que no dañen el ambiente o la vida y la salud de las personas (Aldana, 2013, p. 334).

Actualmente, el OEFA se constituye en el rector del SINEFA y se encarga de fiscalizar a los administrados que actúan en los sectores de minería (mediana y gran minería), energía (hidrocarburos y electricidad), pesquería (procesamiento pesquero industrial y acuicultura de mayor escala) e industria manufacturera (rubros de cerveza, papel, cemento, curtiembre, fundición de metales, biocombustible, elaboración de bebidas y otros). Además, como ente rector, supervisa a las entidades de fiscalización ambiental de los ámbitos nacional, regional y local, que se encargan de fiscalizar las demás actividades económicas. Destaca, en adición, la labor normativa que en materia de supervisión ha aprobado esta entidad, destacando el "Reglamento de Supervisión", aprobado por la Resolución de Consejo Directivo 006-2019-OEFA/CD, el cual establece disposiciones y criterios que regulan el ejercicio de la función de supervisión en el marco del SINEFA y de otras normas que atribuyen dicha función al OEFA. Dicho cuerpo normativo tiene por finalidad verificar el cumplimiento de las obligaciones fiscalizables de los titulares de actividades cuya supervisión se encuentra a cargo del OEFA y promover la subsanación voluntaria de los incumplimientos de dichas obligaciones. Este reglamento acoge como uno de sus principios la "supervisión basada en evidencia", que indica que las acciones de supervisión deben ser planificadas, ejecutadas y concluidas tomando en cuenta información objetiva recabada en el ejercicio de sus funciones. ii) La supervisión de la calidad educativa por parte de la SUNEDU

La Ley 30220 - Ley Universitaria, introdujo una nueva regulación aplicable a las universidades bajo cualquier modalidad, públicas, privadas, nacionales o extranjeras, dentro del territorio nacional y creó a la Superintendencia Nacional de Educación Superior Universitaria (SUNEDU) como organismo técnico especializado adscrito al Ministerio de Educación, con autonomía técnica, funcional, económica, presupuestal y administrativa, para el ejercicio de sus funciones. La SUNEDU asume entre sus funciones la supervisión de la calidad de la prestación del servicio educativo; la supervisión de las condiciones básicas de calidad exigibles para el funcionamiento de las universidades; y, la fiscalización del uso educativo de los recursos públicos, la reinversión de excedentes y los beneficios otorgados por el marco legal a las universidades. En el cumplimiento de estas labores, la SUNEDU se encuentra facultada a dictar normas y establecer procedimientos para asegurar el cumplimiento de las políticas públicas del sector educación en materia de su competencia. Adicionalmente, el artículo 23 de la Ley 30220 la habilita a establecer mecanismos de articulación y coordinación intersectorial para implementar mecanismos de supervisión, seguimiento, evaluación y monitoreo, al igual que indicadores de gestión para la mejora continua.

El artículo 43 del Reglamento de Organización y Funciones de la SUNEDU, aprobado por Decreto Supremo 012-2014-MINEDU, dispone que la Dirección de Supervisión es el órgano de línea encargado de dirigir, coordinar y ejecutar el proceso de supervisión de las universidades, filiales, facultades, escuelas y programas de estudios conducentes a grado académico. Las obligaciones supervisables de competencia de la SUNEDU son aquellas obligaciones derivadas de la Ley Universitaria y de la normativa conexa, de los documentos normativos de carácter general emitidos por la SUNEDU, de los mandatos emitidos por ella, así como de la normativa interna emitida por las universidades. 
Finalmente, destaca dentro de las labores realizadas por la SUNEDU, la aprobación de su "Reglamento de Supervisión", mediante Resolución de Consejo Directivo 006-2017-SUNEDUCD. Este cuerpo reglamentario detalla los tipos de supervisión a ser realizados por esta entidad, así como las etapas de la misma, desde su planificación, pasando por su ejecución y el detalle de los resultados. Del mismo modo, se recogen disposiciones en materia de facultades y deberes del órgano sancionador, así como los derechos y deberes de los supervisados.

iii) La supervisión de la prestación adecuada del servicio de salud por SUSALUD

Mediante la Ley 29344 fue creada la Superintendencia Nacional de Aseguramiento en Salud, como organismo público técnico especializado, adscrito al Ministerio de Salud, con autonomía técnica, funcional, administrativa, económica y financiera, encargada de registrar, autorizar, supervisar y regular a las instituciones administradoras de fondos de aseguramiento en salud, así como supervisar a las instituciones prestadoras de servicios de salud en el ámbito de su competencia, a fin de velar por el aseguramiento universal en salud y su promoción; el uso eficiente y oportuno de los fondos destinados a dicho proceso; la calidad, puntualidad, eficiencia y eficacia de la provisión de las prestaciones; la reglamentación de la recolección, transferencia y difusión de la información por parte de los agentes vinculados al proceso de aseguramiento universal; el establecimiento de mecanismos de conciliación y arbitraje entre los usuarios y las instituciones prestadoras y financiadoras, vinculados al proceso de aseguramiento universal en salud; y, la transparencia y accesibilidad de la información en resguardo de los derechos de los asegurados. Esta entidad, además, registra, autoriza, regula y supervisa el funcionamiento de las entidades prepagadas de salud y a todas aquellas entidades públicas, privadas o mixtas que ofrezcan servicios en la modalidad de pago regular y anticipado. Posteriormente, en el marco de la reforma de la salud, el Decreto Legislativo 1158 modificó la denominación de Superintendencia Nacional de Aseguramiento en Salud por el de Superintendencia Nacional de Salud (SUSALUD).

De acuerdo al artículo 8 del Decreto Legislativo 1158, las funciones generales de SUSALUD se encuentran estrechamente referidas a la supervisión del servicio de salud, destacando entre ellas:

- Promover, proteger y defender los derechos de las personas al acceso a los servicios de salud, supervisando que las prestaciones sean otorgadas con calidad, oportunidad, disponibilidad y aceptabilidad, con independencia de quien las financie, así como los que correspondan en su relación de consumo con las IAFAS o IPRESS, incluyendo aquellas previas y derivadas de dicha relación.
- Supervisar que el uso de los recursos destinados a la provisión de los servicios de salud y de los fondos destinados al Aseguramiento Universal en Salud, garanticen la calidad, oportunidad, disponibilidad y aceptabilidad de las prestaciones.Supervisar a las IPRESS y UGIPRESS y, en el marco de protección de los derechos en salud, de ser pertinente, recomendar el inicio de proceso administrativo, civil y/o penal al o los involucrados, así como realizar el seguimiento de dicha acción.

- Supervisar la calidad, oportunidad, disponibilidad y transparencia de la información generada u obtenida por las IAFAS, IPRESS y Unidades de Gestión de IPRESS, de acuerdo al marco legal vigente.

SUSALUD tiene facultades para realizar la actividad de supervisión, pudiendo actuar sobre todas las Instituciones Prestadoras de Salud (IPRESS), así como las Instituciones Administradoras de Fondos de Aseguramiento en Salud (IAFAS), públicas, privadas y mixtas del país.

En el marco de sus funciones, el Decreto Supremo 034-2015-SA aprobó el Reglamento de Supervisión de SUSALUD, enfatizando que ésta se desarrolla con base a la metodología de inspección, vigilancia y control sobre las IAFAS, IPRESS y Unidades de Gestión de IPRESS públicas, privadas y mixtas, bajo un enfoque de cumplimiento normativo, gestión del riesgo, promoción y protección de derechos en salud. Además, este Reglamento regula cuatro etapas de la supervisión a cargo de SUSALUD: planificación, ejecución, informes y seguimiento. Este Reglamento destaca también por incluir exigencias y garantías a favor de los supervisados, a efectos de garantizar el adecuado ejercicio de la fiscalización administrativa (obligaciones de los supervisores), pero también introduce una clasificación propia de tipos de actas de supervisión (de sesión de inicio, de sesiones de trabajo y de sesión de cierre).

iv) La supervisión de obligaciones laborales por la SUNAFIL

Mediante la Ley 29981 se crea la Superintendencia Nacional de Fiscalización 
Laboral (SUNAFIL) como organismo técnico especializado adscrito al Ministerio de Trabajo y Promoción del Empleo, responsable de promover, supervisar y fiscalizar el cumplimiento del ordenamiento jurídico sociolaboral y el de seguridad y salud en el trabajo, así como brindar asesoría técnica, realizar investigaciones y proponer la emisión de normas sobre dichas materias. De acuerdo al artículo 2 de la Ley 30814, la SUNAFIL es la autoridad central del Sistema de Inspección del Trabajo y como tal, dicta normas y establece procedimientos para asegurar el cumplimiento de las políticas públicas en materia de su competencia que requieren de la participación de otras entidades del Estado.

Entre las funciones de la SUNAFIL se encuentran principalmente las siguientes:

- Supervisar el cumplimiento de la normativa sociolaboral, ejecutando para ello las funciones de fiscalización dentro del ámbito de su competencia.

- Aprobar las políticas institucionales en materia de inspección del trabajo, en concordancia con las políticas nacionales y sectoriales.

- Formular y proponer las disposiciones normativas de su competencia.

- Vigilar y exigir el cumplimiento de las normas legales, reglamentarias, convencionales y las condiciones contractuales.

- Fomentar y brindar apoyo para la realización de actividades de promoción de las normas sociolaborales, así como para el desarrollo de las funciones inspectivas de orientación y asistencia técnica de los gobiernos regionales.

Por otro lado, conforme con el artículo 3 de la Ley 29981, la SUNAFIL también cuenta con las funciones y competencias establecidas en el artículo 3 de la Ley 28806 - Ley General de Inspección del Trabajo. En ese sentido, de acuerdo con el artículo 3 de la Ley 28806, las finalidades de la inspección de la SUNAFIL son principalmente la vigilancia y exigencia del cumplimiento de las normas legales, reglamentarias, convencionales y condiciones contractuales, sean estas parte del régimen de común aplicación o de los regímenes especiales; y, la orientación y asistencia técnica.

De acuerdo a la Ley General de Inspección del Trabajo, en el marco de las funciones de inspección, los inspectores de trabajo están facultados para, entre otros, entrar libremente a cualquier hora del día o de la noche a cualquier centro de trabajo, establecimiento o lugar sujeto a inspección y a permanecer en el mismo, sin previo aviso; practicar cualquier diligencia de investigación, prueba o examen que considere necesario para comprobar que las disposiciones legales se estén cumpliendo correctamente; y recabar u obtener información, datos o antecedentes con relevancia para el cumplimiento de su función.

\section{v) Supervisión del transporte}

La fiscalización administrativa en el ámbito del transporte involucra, tal vez, uno de los sectores con mayores entramados a nivel de autoridades y ámbitos de competencia involucrados. No solo a nivel del Gobierno Nacional, desde el Ministerio de Transportes y Comunicaciones y la actual Superintendencia Nacional de Transporte Terrestre de Personas, Carga y Mercancías (SUTRAN), sino también a nivel de Gobiernos Regionales y Locales, destacando adicionalmente el tratamiento de Lima y Callao y la creación, en el espacio de estos últimos, de la Autoridad de Transporte Urbano para Lima y Callao (ATU). Lo que busco resaltar en este apartado son dos cuestiones: primero, la dispersión normativa en materia de supervisión o fiscalización administrativa en transporte y, segundo, cómo las obligaciones en este sector han demandado con los años la creación y fortalecimiento de nuevas organizaciones administrativas para cumplir con el ejercicio efectivo de este rol.

De acuerdo a la Ley 27181 - Ley General de Transporte y Tránsito, la actividad de fiscalización comprende la supervisión, detección de infracciones y la imposición de sanciones por incumplimiento de los dispositivos legales vinculados al transporte y al tránsito terrestre. En los mismos términos lo señala el Reglamento Nacional de Administración de Transporte, aprobado por Decreto Supremo 017-2009-MTC, según el cual la fiscalización del servicio de transporte es función exclusiva de la autoridad competente en el ámbito de su jurisdicción, salvo que por otra norma con rango de ley se disponga lo contrario.

El Ministerio de Transportes y Comunicaciones (MTC), es el encargado de fiscalizar el cumplimiento de las normas sobre el servicio de transporte terrestre del ámbito de su competencia, para lo cual puede contratar empresas o instituciones especializadas en el campo de la supervisión (transporte interprovincial de ámbito nacional y transporte internacional). La Ley 29380 creó la SUTRAN, como organismo adscrito al MTC, con personería jurídica de derecho público interno y autonomía técnica, funcional, administrativa y presupuestal. En lo que 
respecta a sus funciones, conviene enumerar las siguientes (relevantes para este estudio):

- Supervisar, fiscalizar y sancionar a los titulares de los servicios de transporte terrestre de los ámbitos nacional e internacional, a los conductores habilitados para el servicio y a los titulares y operadores de infraestructura complementaria de transporte, por los incumplimientos o infracciones en que incurran.

- Supervisar y fiscalizar la circulación de vehículos en la red vial bajo su competencia, velando por el cumplimiento de lo dispuesto por el Reglamento Nacional de Tránsito y el Reglamento Nacional de Vehículos, sancionando a quien corresponda, por las infracciones o incumplimientos de estos.

- Supervisar, fiscalizar y sancionar a los titulares de autorizaciones, concesionarios y prestadores de servicios complementarios, inspecciones, certificaciones, verificaciones y otras relacionadas con el transporte y tránsito terrestre.

- Administrar el régimen de imposición de papeletas por las infracciones de tránsito detectadas en la red vial bajo su competencia.

Se observa que la SUTRAN ejerce la acción de supervisión, fiscalización, control y sanción, en las vías de carácter nacional, las mismas que no se encuentran dentro del ámbito urbano, ni bajo las competencias de los gobiernos regionales o locales.

Por su parte, los Gobiernos Regionales tienen, en materia de transporte, competencia normativa, de gestión y fiscalización, conforme a lo señalado en el artículo 56 de la Ley 27867 - Ley Orgánica de Gobiernos Regionales. Dicho dispositivo señala entre las funciones de este nivel de gobierno la de supervisar y fiscalizar la gestión de actividades de infraestructura de transporte vial de alcance regional, así como autorizar supervisar, fiscalizar y controlar la prestación de servicios de transporte interprovincial dentro del ámbito regional en coordinación con los gobiernos locales.

Por su lado, los Gobiernos Locales asumen las siguientes funciones. En lo que se refiere a las municipalidades provinciales, éstas supervisan, detectan infracciones e imponen sanciones por incumplimiento de los dispositivos legales vinculados al transporte y al tránsito terrestre y fiscalizan las concesiones de infraestructura vial que otorgue la municipalidad provincial en su respectiva jurisdicción, en concordancia con los reglamentos nacionales. De otro lado, las municipalidades distritales realizan aquellas funciones que los reglamentos nacionales y las normas emitidas por la municipalidad provincial respectiva les señalen y, en particular, la regulación del transporte menor (mototaxis y similares).

Sobre el particular, conviene indicar el caso particular de Lima y la Provincia Constitucional del Callao. La Ley 30900
- Ley que creó la ATU, introdujo un nuevo organismo competente para planificar, regular, gestionar, supervisar, fiscalizar y promover la eficiente operatividad del sistema integrado de transporte de Lima y Callao para lograr una red integrada de servicios de transporte terrestre urbano masivo de pasajeros. La ATU ejerce competencia sobre el servicio público de transporte terrestre de personas que se presta dentro del territorio de la provincia de Lima y de la provincia Constitucional del Callao, así como en las provincias contiguas a éstas y que en su integridad guardan entre sí, continuidad urbana (la que debe ser declarada con arreglo al procedimiento legalmente establecido).

De esta forma, las actividades de fiscalización en el sector transporte son distribuidas de la siguiente forma: en el transporte interprovincial del ámbito nacional y transporte internacional tienen competencia el MTC y la SUTRAN; en el transporte interprovincial del ámbito regional, los gobiernos regionales; en el transporte urbano, las municipalidades provinciales; para el caso de Lima y Callao, la ATU; y, en la regulación del transporte menor, las municipalidades distritales.

\section{El marco normativo común de la actividad de fiscalización administrativa de acuerdo al TUO de la Ley 27444}

El 21 de diciembre del 2016, se publicó en el Diario Oficial "El Peruano" el Decreto Legislativo 1272, Decreto Legislativo por el cual se modificó la Ley del Procedimiento Administrativo General y se derogó la Ley 29060, Ley del Silencio Administrativo. El referido Decreto Legislativo introdujo una serie de importantes modificaciones, siendo una de las principales la inclusión de un capítulo dedicado a desarrollar de forma exclusiva los principios estructurales y comunes al ejercicio de la potestad de fiscalización en el ordenamiento peruano. La importancia de esta reforma radica en que, previamente a esta inclusión, la regulación del ejercicio de esta actividad se encontraba dispersa y era definida tan solo en función al sector 
encargado de verificar el cumplimiento de sus obligaciones, todo ello mediante una entidad estatal determinada. En consecuencia, no existía un panorama claro y unívoco respecto a los deberes, garantías y derechos a ser respetados en la realización de esta actividad. Estas razones fueron recogidas en la Exposición de Motivos del Decreto Legislativo 1272, en la cual se advirtió que esta situación de heterogeneidad creaba "las condiciones para la operación ineficiente de la fiscalización administrativa y la carencia de predictibilidad, de seguridad jurídica y de coherencia para la aplicación de las legislaciones sectoriales, lo que inclusive puede resultar lesivo al público y a los derechos de los ciudadanos".

De esta manera, con la inclusión del capítulo de fiscalización en el actual TUO LPAG, se brinda un régimen jurídico uniforme y de cumplimiento obligatorio para todas las entidades competentes encargadas de realizar dicha actividad, estableciendo garantías y obligaciones para el administrado, así como deberes a cargo de la Administración. Conforme a esta nueva normativa común, la actividad de fiscalización es definida en el artículo 239 del TUO LPAG de la siguiente manera:

"239.1 La actividad de fiscalización constituye el conjunto de actos y diligencias de investigación, supervisión, control o inspección sobre el cumplimiento de las obligaciones, prohibiciones y otras limitaciones exigibles a los administrados, derivados de una norma legal o reglamentaria, contratos con el Estado u otra fuente jurídica, bajo un enfoque de cumplimiento normativo, de prevención del riesgo, de gestión del riesgo y tutela de los bienes jurídicos protegidos".

Como puede observarse, al definir la actividad de fiscalización, la legislación ha realizado una equiparación entre los distintos términos por los que dicha actividad era aludida en la normativa y en la doctrina, pero también contiene disposiciones que no han escapado de la discusión académica. Es el caso, por ejemplo, respecto a la naturaleza de la fiscalización, sobre la cual algunos autores la refieren como un "procedimiento administrativo especial" sujeto a su régimen propio, pero regido en caso contrario por la norma supletoria (Morón, 2017, p. 345); mientras que otros, siguiendo la literalidad del TUO LPAG, la definen más bien como una "actividad material" (Zegarra, 2018). Sobre este mismo tema, el Ministerio de Justicia y Derechos Humanos (MINJUS) ha señalado que la fiscalización no constituye un procedimiento administrativo, sino un conjunto de actividades realizadas a fin de verificar el cumplimiento del marco jurídico, por lo que tampoco tiene como fin la emisión de un acto administrativo.

Así, según lo anteriormente citado, la actividad de fiscalización es ejercida por la Administración Pública de manera potestativa, es decir, la Administración no se encuentra obligada a realizar acciones de fiscalización de manera específica, sino que la misma será realizada a través de una adecuada planificación y en atención a la relevancia para el interés público de realizar determinadas fiscalizaciones. Algunas materias, por la relevancia o sensibilidad de las mismas, contarán con planes más elaborados en virtud a la magnitud de los daños que pueden derivarse del incumplimiento de las obligaciones o prohibiciones. En otros casos, la atención será menor, pero sin omitir la responsabilidad de la Administración Pública de estar presta y atenta a vigilar progresivamente la atención de estas obligaciones por menores que sean.

Los principales aspectos legales que respecto a la fiscalización administrativa ha recogido el TUO LPAG han generado importantes estudios a los cuales me remito (Zegarra, 2018; Morón, 2018). Sin embargo, quiero llamar brevemente la atención respecto a las garantías, derechos y obligaciones que el TUO LPAG ha tenido a bien considerar como estándar común o mínimo para el ejercicio de esta potestad, vinculando no solo a quienes realizan la labor de fiscalización (incluso, aquellos que por delegación pueden ejercerla), sino también a quienes son fiscalizados (con el mandato, además, de que las entidades adecúen sus normativas a estas disposiciones).

\subsection{Homogeneidad para enmarcar las fa- cultades de quienes ejercen actividad de fiscalización}

EI TUO LPAG ha dispuesto que los actos y diligencias de fiscalización se inician siempre de oficio, ya sea por iniciativa propia o por orden superior, petición motivada o denuncia. Al ejercer actividad de fiscalización, el TUO ha procurado enumerar las facultades que ésta le atribuye a las entidades competentes.

Por un lado, en ejercicio de esta potestad, la entidad puede requerir al administrado objeto de la fiscalización, la exhibición o presentación de todo tipo de documentación, expedientes, archivos u otra información necesaria, respetando el principio de legalidad. Claro está que la información que se requiera, deberá tener conexión con el objeto materia de fiscalización y con los bienes jurídicos involucrados dentro de la competencia de la autoridad fiscalizadora. Caso contrario, la fiscalización administrativa estaría ejerciéndose ilegalmente y toda información a la que se accediera tendría que invalidarse $o$, eventualmente, justificar el archivo del procedimiento sancionador $\mathrm{o}$, incluso, la nulidad del acto de sanción. Esta 
disposición, por tanto, exige un parámetro de proporcionalidad y conexidad entre aquella información que se exige y el bien tutelado con ocasión de la fiscalización.

Asimismo, como parte de las facultades de fiscalización, la autoridad puede interrogar a las personas supervisadas o a sus representantes, empleados, funcionarios, asesores y a terceros, utilizando los medios técnicos que considere necesarios para generar un registro completo y fidedigno de sus declaraciones. Es decir, la actuación material de interrogar no debe verse limitada únicamente a recibir respuestas por parte de quienes ejercen la representación legal o formal del agente supervisado, sino que, en clara relación al propósito de constatar y recoger a detalle los hechos advertidos, la fiscalización flexibiliza este criterio y legitima la formulación de preguntas a todo agente que pueda aportar hechos o pruebas respecto a una supervisión, incluyendo esto a terceros ajenos a toda relación (fáctica o formal) con el administrado supervisado. Desde luego, al menos en mi posición, es necesario precisar que mientras menor sea el vínculo entre un interrogado y el supervisado, menor deberá ser también el estándar para evaluar si este interrogado puede calificar como obstructor a una supervisión al negarse o al afirmar que no tiene razones por las cuales responder a las preguntas del supervisor.

De igual modo, las entidades con competencias fiscalizadoras pueden realizar inspecciones, con o sin previa notificación, en los locales y/o bienes de las personas naturales o jurídicas objeto de las acciones de fiscalización, respetando el derecho fundamental a la inviolabilidad del domicilio cuando corresponda. En efecto, ésta es una de las principales facultades de las entidades fiscalizadoras, pues permite apreciar in situ la situación respecto al cumplimiento o no de las obligaciones a cargo de los administrados. Muchas de las entidades listadas con ocasión de este estudio ya recogían esta facultad en sus respectivos marcos normativos, previendo sobre todo inspecciones inopinadas, de modo que pudiera apreciarse el desenvolvimiento regular de los supervisados en un momento ordinario en el desempeño de sus actividades. El límite a esta facultad, desde luego, se encuentra en la inviolabilidad del domicilio, cuestión que requiere de una autorización judicial previa(17).

Por otro lado, la fiscalización faculta a la entidad a tomar copia de los archivos físicos, ópticos, electrónicos u otros, así como tomar fotografías, realizar impresiones, grabaciones de audio o en video con conocimiento previo del administrado $y$, en general, utilizar los medios necesarios para generar un registro completo y fidedigno de su acción de fiscalización. Ésta es, sin duda, de las facultades ordinarias más comunes en su empleo por parte de las autoridades administrativas. La tecnología, al día de hoy, no limita el "copiado" a un proceso físico, sino también al acceso o "descarga" de archivos en soporte virtual ("en la nube"). De hecho, la tecnología ofrece instrumentos y programas para acceder y descargar información de titularidad del supervisado por medio de programas que se conectan a la base de datos de éste (sobre todo cuando se trata de personas jurídicas). El filtro de la información pertinente se realiza por medio de estos programas, pero la obligación del supervisor se extiende de forma posterior, a efectos de que toda información confidencial o no pertinente con el objeto de supervisión no sea empleada o, en todo caso, sea suprimida o no considerada en el expediente.

Por su parte, la fiscalización faculta a realizar exámenes periciales sobre la documentación y a utilizar en las acciones y diligencias de fiscalización equipos que se consideren necesarios. El empleo de la ciencia y de evaluaciones técnicas en la fiscalización es una constante en aquellos sectores que por su especialidad se apoyan en ella, a efectos de evidenciar cuestiones que no son perceptibles de otro modo. El empleo de equipos va de la mano con esto, pues permite, entre otras cuestiones, tomar muestras para exámenes posteriores de laboratorio, cuestión recurrente en sectores como el medioambiental, pero no solo ello, los equipos involucran, además, todos aquellos dispositivos que permitan al supervisor desenvolverse adecuadamente y efectivamente en el ejercicio de dicho poder.

Finalmente, el TUO LPAG reconoce como facultad del fiscalizador el poder ampliar o variar el objeto de la acción de fiscalización en caso que, como resultado de las acciones y diligencias realizadas, se detecten incumplimientos adicionales a los expresados inicialmente en el referido objeto. Esto se enuncia expresamente por el legislador, pues la práctica demostraba que durante las fiscalizaciones, las autoridades podían tomar conocimiento de otras prácticas realizadas por el supervisado, pero que no se enmarcaban dentro del propósito u objeto inicial de la fiscalización. En algunos

(17) Temas adicionales como qué califica como domicilio, el domicilio en casos de personas jurídicas, entre otros, son discusiones recurrentes en la práctica y dogmática administrativa, sin embargo, rebasan el objeto del presente. 
casos, incluso, ni en el ámbito de sus competencias. Soy de la posición que la fiscalización, precisamente por su naturaleza instrumental y maleable, no puede encasillarse y predeterminarse plenamente en su ejercicio con anterioridad al desarrollo de la supervisión. Es un imposible material el predeterminar el alcance que pueden tener las labores de la autoridad durante una fiscalización. Exigir algo similar supondría limitar fácticamente el ejercicio de esta potestad y, lo que es peor, inutilizarla, pues la predicción de aquello que podrá acontecer en los hechos durante el desarrollo de la supervisión no es conocido ni siquiera por el supervisado y, en todo caso, sería una exigencia que jugaría injustificadamente a favor de este último, en desmedro del bien jurídico que busca tutelarse.

\subsection{Reglas comunes en torno a los deberes que deben observar quienes ejercen fiscalización administrativa}

Si bien el desarrollo de una fiscalización no configura propiamente el trámite de un procedimiento administrativo, esto no es óbice para que el ejercicio de esta potestad deba observar un conjunto de formalidades que, si bien no obedecen a la exigencia de un debido procedimiento (pues no lo hay), sí se requieren en la dinámica de la constitucionalización del Derecho (para resguardar los derechos de las personas involucradas) y, además, en los límites que el Derecho administrativo, por definición, procura respecto a todo ejercicio de poder. En tal sentido, el TUO LPAG recoge importantes referencias a modo de "deberes", que bien podrían ser calificadas como "garantías" a favor del administrado supervisado.

Entre estos deberes se enuncia la revisión o evaluación previa que de la documentación que contenga información relacionada con la materia que será objeto de fiscalización debe realizar la autoridad, es decir, la fiscalización procurará realizarse in situ o en ejercicio pleno de las facultades que se enumeraron en el punto anterior, previa revisión del marco normativo y de la información que, sin recurrir propiamente a la inspección, obra en disposición de la autoridad administrativa. Esto denota, más que una garantía propiamente del fiscalizado, una exigencia para que la fiscalización sea ejercida idónea y efectivamente para la tutela del bien jurídico correspondiente. Esto permitirá, además, que los servidores se encuentren informados y preparados para desarrollar la fiscalización de forma más enfocada (Morón, 2018, p. 1574) y justificadamente menos invasiva.

Por otro lado, se enuncian otros deberes formales a cargo del supervisor, como identificarse a requerimiento de los administrados, presentando la credencial otorgada por su entidad, así como su documento nacional de identidad; citar la base legal que sustenta su competencia de fiscalización, sus facultades y obligaciones, al administrado que lo solicite; entregar copia del acta de fiscalización o documento que haga sus veces al administrado al finalizar la diligencia de inspección, consignando de manera clara y precisa las observaciones que formule el administrado; guardar reserva sobre la información obtenida en la fiscalización; y, el deber de imparcialidad y prohibición de mantener intereses en conflicto.

\subsection{Derechos y obligaciones comunes de todo administrado que es objeto de fiscalización}

EITUO LPAG se ha preocupado por recoger los derechos y obligaciones de los administrados que son objeto de fiscalización. Así, se recoge el derecho a ser informado del objeto y del sustento legal de la acción de supervisión. Considero que, de este modo, el particular podrá advertir o cuestionar, de corresponder, las competencias de la autoridad para dicha fiscalización, así como prestar su disposición a brindar la información pertinente en función al objeto materia de supervisión o cuestionar (y dejar constancia de ello en el acta) el requerimiento de información que no guarda conexidad con el bien jurídico que se procura tutelar. EI TUO LPAG agrega que, de ser previsible, se comunique al administrado el plazo estimado de duración de la fiscalización, así como de sus derechos y obligaciones en el curso de tal actuación.

Al administrado le asiste también el derecho a requerir las credenciales y el documento nacional de identidad de los funcionarios, servidores o terceros a cargo de la fiscalización; poder realizar grabaciones en audio o video de las diligencias en las que participen; y requerir que se incluyan sus observaciones en las actas correspondientes. No solo ello, sino que una vez concluida la visita inspectiva, el administrado puede presentar documentos, pruebas o argumentos adicionales con posterioridad a la recepción del acta correspondiente. Asimismo, aunque no es una condición para el desarrollo de la fiscalización, el TUO LPAG recoge la posibilidad de que el administrado cuente con asesoría profesional durante las diligencias.

Por último, el administrado supervisado debe observar un conjunto de obligaciones que procuran que la actividad de fiscalización pueda realizarse adecuadamente y de acuerdo a sus fines. Por ello, se prevé que el administrado debe realizar o brindar todas las 
facilidades para ejecutar las facultades que asisten a la autoridad fiscalizadora y, sobre todo, permitir el acceso de los funcionarios, servidores y terceros fiscalizadores, a sus dependencias, instalaciones, bienes y equipos, de administración directa o no, sin perjuicio de su derecho fundamental a la inviolabilidad del domicilio cuando corresponda; es decir, una labor de no obstrucción al desarrollo de esta actividad, debiendo suscribir el acta de fiscalización (en caso negarse, se dejará constancia de ello).

\section{Conclusión}

En el presente estudio he podido dar cuenta de la evolución normativa de la actividad de fiscalización administrativa en el ordenamiento peruano, desde una óptica general y, sobre todo, a partir de los cambios que el Estado ha atravesado desde 1979. Se aprecia, desde el caso peruano, cómo la fiscalización administrativa fue amoldándose a los objetivos perseguidos por el Estado, advirtiéndose una fiscalización nula o aparente bajo el Estado empresario de la Constitución de 1979 y, más bien, una fiscalización tecnificada y especializada bajo el nuevo rol garante de éste bajo la Constitución de 1993.

La dispersión o heterogeneidad normativa de la que fue objeto la fiscalización hasta la dación del Decreto Legislativo 1272 a fines del año 2016, exigió que el TUO LPAG introdujera un nuevo capítulo normativo dirigido únicamente a regular de forma común el ejercicio de la actividad fiscalizadora. Esto significó que, posteriormente, las entidades con competencias para ello, adecuaran sus respectivos reglamentos de supervisión a los nuevos estándares y garantías ahí previstos.

Finalmente, cabe destacar dentro de estos nuevos estándares, el nuevo enfoque que el TUO LPAG le ha brindado a la fiscalización administrativa: "un enfoque de cumplimiento normativo, de prevención del riesgo, de gestión del riesgo y tutela de los bienes jurídico protegidos". Como ya lo he indicado en otra ocasión (Sánchez Povis, 2019), el enfoque que propone el TUO LPAG está inclinado más bien a priorizar el conocimiento e identificación de obligaciones por parte de los particulares y a conducirlos ordenada y progresivamente a su cumplimiento. De esta forma, el enfoque del TUO LPAG plantea una fiscalización cooperante con el actuar privado para lograr el mayor propósito de esta potestad: que los administrados finalmente cumplan. Se persigue, por tanto, la prevención del incumplimiento, a efectos de evitar la comisión de una infracción y su posterior sanción, o el restablecimiento de la situación legal procurada por el ordenamiento jurídico. La fiscalización no debe ser entendida como el paso previo que indefectiblemente derivará en un procedimiento sancionador y en una sanción, sino en ese "instrumento" que bien reconocemos en ella, pero ahora abocada al propósito principal que es lograr un "estado de cumplimiento y respeto de las obligaciones jurídicoadministrativas".

\section{Referencias bibliográficas}

Aldana Durán, M. (2013). La Fiscalización Ambiental en el Perú: Orígenes, Estado Actual y Perspectivas Futuras Martha Inés Aldana Durán. Revista Derecho \& Sociedad 41, p. 323-340.

Bermejo, J. (2000). La administración inspectora. En Sosa, F. (coordinador). El Derecho Administrativo en el umbral del siglo XXI (p. 1253-1270). Valencia: Tirant lo Blanch.

Canals i Ametller, D. (2003). El ejercicio por particulares de funciones de autoridad. Control, inspección y certificación. Granada: Comares.

Congreso del Perú (1982). Ley $N^{\circ} 23406$. Ley General de Electricidad. Diario Oficial El Peruano, 29 de mayo.

(1996). Ley $\mathrm{N}^{\circ} 26734$ que crea el Organismo Supervisor de la Inversión en Energía (OSINERG). Diario Oficial El Peruano, $31 \mathrm{de}$ diciembre.

(1998). Ley N² 26917. Ley de Supervisión de la Inversión Privada en Infraestructura de Transporte de Uso Público y Promoción de los Servicios de Transporte Aéreo. Diario Oficial El Peruano, 23 de enero.

(1999). Ley $N^{\circ} 27181$. Ley General de Transporte y Tránsito. Diario Oficial El Peruano, 7 de octubre.

. (2000). Ley N² 27332. Ley Marco de los Organismos Reguladores de la Inversión Privada en los Servicios Públicos. Diario Oficial El Peruano, 29 de julio.

(2002). Ley № 27867. Ley Orgánica de Gobiernos Regionales. Diario Oficial El Peruano, 16 de noviembre.

(2006). Ley $N^{\circ} 28806$. Ley General de Inspección del Trabajo. Diario Oficial El Peruano, 19 de julio.

(2007). Ley $\mathrm{N}^{\circ} 28964$. Ley que transfiere competencias de supervisión y fiscalización de las actividades mineras al OSINERG. Diario Oficial EI Peruano, 24 de enero.

(2009). Ley $\mathrm{N}^{\circ} 29380$. Ley que crea la Superintendencia de Transporte Terrestre de personas, carga y mercancías SUTRAN. Diario Oficial El Peruano, 16 de junio.

(2009). Ley N²9325. Ley del Sistema Nacional de Evaluación y Fiscalización Ambiental. Diario Oficial El Peruano, 4 de marzo.

(2009). Ley $N^{\circ} 29344$. Ley marco de aseguramiento universal en salud. Diario Oficial El Peruano, 9 de abril. 
(2013). Ley $N^{\circ} 30011$. Ley que modifica la Ley 29325, Ley del Sistema Nacional de Evaluación y Fiscalización Ambiental. Diario Oficial El Peruano, 25 de abril.

(2013). Ley $N^{\circ}$ 29981. Ley que crea la Superintendencia Nacional de Fiscalización Laboral SUNAFIL. Diario Oficial EI Peruano, 15 de enero.

(2014). Ley $\mathrm{N}^{\circ}$ 30220. Ley Universitaria. Diario Oficial El Peruano, 8 de julio.

. (2018). Ley $\mathrm{N}^{\circ}$ 30814. Ley de fortalecimiento del sistema de inspección del trabajo. Diario Oficial El Peruano, 5 de julio.

(2018). Ley $\mathrm{N}^{\circ}$ 30900. Ley que crea la autoridad de transporte urbano para Lima y Callao ATU. Diario Oficial EI Peruano, 8 de diciembre.

(2019). Ley $N^{\circ}$ 30905. Ley que modifica el artículo 35 de la Constitución Política del Perú. Diario Oficial El Peruano, 9 de enero.

Constitución Política del Perú (1979). 12 de julio de 1979. Disponible en: http://www.leyes.congreso.gob.pe/Documentos/constituciones ordenado/CONSTIT_1979/Cons1979_TEXTO_CORREGIDO.pdf.

Constitución Política del Perú (1993). 31 de diciembre de 1993. Disponible en: http://www.leyes.congreso.gob.pe/Documentos/ constituciones_ordenado/CONSTIT_1993/Texto_actualizado_ CONS_1993.pdf.

Dammert, A. (2010). Evolución reciente y perspectivas del sector eléctrico peruano. En García Delgado, J. (Editor). Perspectivas de la regulación energética en Iberoamérica (p. 61-82). Madrid: Civitas.

Danós, J. (2004). Los organismos reguladores de los servicios públicos en el Perú: su régimen jurídico, organización, funciones de resolución de controversias y de reclamos de usuarios. En Ochoa, J. y otros. Derecho Administrativo (p. 415-456). Lima: Jurista Editores.

Esteve Pardo, J. (2007). La regulación de la economía desde el Estado garante. En Asociación Española de Derecho Administrativo. La Autonomía municipal, administración y regulación económica, títulos académicos y profesionales (p. 79-126). Santander: Thomson Reuters Aranzadi.

. (2014). Lecciones de Derecho Administrativo (4ta Edición). Madrid: Marcial Pons.

(2015). La Administración Garante. Una aproximación. En Revista de Administración Pública. Madrid: Centro de Estudios Políticos y Constitucionales. $N^{\circ}$ 197. 2015. pp. 11-39.

Fernández Ramos, S. (2002). La actividad administrativa de inspección. El régimen jurídico general de la función inspectora. Granada: Ed. Comares.

Flores - Aráoz, A. (2017). ¿Hay autonomía universitaria? Lima: Universidad Ricardo Palma.

García Ureta, A. (2006). La potestad inspectora de las administraciones públicas. Madrid: Marcial Pons.

Gómez, H. y Granados, M. (2013). El fortalecimiento de la fiscalización ambiental. En Gómez Hugo (Compilador). El nuevo enfoque de la fiscalización ambiental. OEFA, Lima.

Izquierdo Carrasco, M. (2019). Fiscalización, supervisión e inspección administrativa: aproximación conceptual crítica y caracteres generales en el Derecho peruano. En Zegarra Valdivia, D (coordinador), La proyección del Derecho Administrativo Peruano. Estudios por el Centenario de la Facultad de Derecho de la PUCP (p. 387-418). Lima: Palestra.

Kresalja Rosselló, B. (1999). El rol del Estado y la gestión de los servicios públicos. En Revista Themis. Lima 39, p. 39-98.

(2015). ¿Estado o Mercado? El principio de subsidiariedad en la Constitución peruana. Lima: Fondo Editorial de la PUCP.

Kresalja Rosselló, B. y Ochoa Cardich, C. (2009). Derecho Constitucional Económica. Lima: Fondo Editorial de la Pontificia Universidad Católica del Perú.

Maldonado Meléndez, M. (2016). Los Organismos Reguladores de los servicios de red del Perú (en comparación con la CNMC española) (Tesis de doctorado en Derecho). Universidad del País Vasco. Recuperado el 13 de abril de 2020. https:// addi.ehu.es/handle/10810/26315

Ministerio de Justicia y Derechos Humanos (2017). Guía de opiniones jurídicas emitidas por la Dirección General de Desarrollo y Ordenamiento Jurídico. p. 149. Recuperado de: https://www. minjus.gob.pe/wp-content/uploads/2017/04/ MINJUS-DGDOJ-GUIA-DE-OPINIONES-DELTUO-DE-LA-27444.pdf

(2019). Decreto Supremo 004 2019-JUS. Texto Único Ordenado de la Ley de Procedimiento Administrativo General. Diario Oficial El Peruano, 25 de enero.

Mir Puigpelat, O. (2004). Globalización, Estado y Derecho. Las Transformaciones Recientes del Derecho Administrativo. Madrid: Editorial Civitas.

Morón Urbina, J.C. (2017). Comentarios a la Ley del Procedimiento Administrativo General (Doceava Edición). Lima: Gaceta Jurídica.

(2018). La nueva regulación común de la actividad administrativa de supervisión en el Derecho peruano. En Moreno Molina, Á. y otros (Coord.) Estudios de Derecho Público en homenaje a Luciano Parejo Alfonso (p. 1549-1600) Madrid: Tirant lo Blanch.

OEFA (2014). La fiscalización ambiental en el Perú: reflexiones sobre las funciones y atribuciones del OEFA. Consulta: 17 de abril de 2020 https://repositorio. oefa.gob.pe/bitstream/handle/123456789/66/ la-fiscalizacion-ambiental-en-el-Peru-reflexionessobre-las-funciones-y-atribuciones-del-Oefa. pdf?sequence $=1 \&$ isAllowed $=y$

(2019). Resolución de Consejo Directivo $\mathrm{N}^{\circ}$ 006-2019-OEFA/CD. Aprueban el "Reglamento de Supervisión". Diario Oficial El Peruano, 17 de febrero. 
Organismo Supervisor de la Inversión en Energía (2004). Resolución de Consejo Directivo No 013-2004-OS/CD. Reglamento de Supervisión de Actividades Energéticas. Diario Oficial El Peruano, 20 de enero.

(2007). Resolución de Consejo Directivo N³ 324-2007OS/CD. Reglamento de Supervisión de Actividades Energéticas y Mineras.

(2009). Resolución de Consejo Directivo N²05-2009-OSCD. Reglamento de Supervisión de Actividades Energéticas y Mineras. Diario Oficial El Peruano, 4 de noviembre.

. (2013). Resolución de Consejo Directivo N¹71-2013-OSCD. Reglamento de Supervisión y Fiscalización de las Actividades Energéticas y Mineras de OSINERGMIN, 15 de agosto.

(2017). Resolución de Consejo Directivo del Organismo Supervisor de la Inversión en Energía y Minería Nº 040-2017-OSCD. Reglamento de Supervisión, Fiscalización y Sanción de las Actividades Energéticas y Mineras a cargo de OSINERGMIN, 9 de marzo.

Organismo Supervisor de Inversión Privada en Telecomunicaciones (1995). Resolución del Consejo Directivo Nㅜ006-CD/95. Procedimiento de Supervisión y Control de la Calidad del Servicio.

(1998). Resolución Nº 050-98-PD-OSIPTEL. Procedimiento para la Supervisión y Control del Indicador Tiempo de Espera para la Conexión (TEC).

(1999). Resolución de Consejo Directivo N 041-99-CDOSIPTEL. Procedimiento de Supervisión y Control de la Calidad del Servicio Público de Telefonía Móvil.

(2005). Resolución de Consejo Directivo Nº 040-2005-CDOSIPTEL. Reglamento de Calidad de los Servicios Públicos de Telecomunicaciones, 16 de junio.

. (2009). Resolución de Consejo Directivo Nº29-2009-CDOSIPTEL. Procedimiento de Supervisión de los Indicadores de Calidad. Diario Oficial EI Peruano, 2 de julio.

(2014). Resolución de Consejo Directivo N 123-2014-CDOSIPTEL. Reglamento General de Calidad de los Servicios Públicos de Telecomunicaciones, 10 de octubre.

OSITRAN (2004). Resolución de Consejo Directivo Nº 007-99-CDOSITRAN. Proyecto de Reglamento General de Supervisión de OSITRAN, 24 de mayo.

(2004). Resolución de Consejo Directivo Nº36-2004-CDOSITRAN. Reglamento General de Supervisión de OSITRAN, 25 de agosto.

(2011). Resolución de Consejo Directivo Nº 024-2011-CDOSITRAN. Reglamento General de Supervisión de OSITRAN, 4 de julio.

(2018). Resolución de Consejo Directivo Nº 009-2018-CDOSITRAN. Reglamento de Incentivos, Infracciones y Sanciones, 4 de abril.

Parejo Alfonso, Luciano (2016a). La vigilancia y la supervisión administrativas. Un ensayo de su construcción como relación jurídica. Madrid: Tirant lo Blanch. (2016b). Estado y Derecho en Proceso de Cambios. Las Nuevas Funciones de Regulación y Garantía del Estado Social de Soberanía Limitada. Madrid: Marcial Pons.

Poder Ejecutivo (1971). Decreto Ley N 19020. Ley General de Telecomunicaciones. Diario Oficial El Peruano, 9 de noviembre.

(1981). Decreto Legislativo 140. Ley de Organización de los Sectores Trabajo y Promoción Social. Diario Oficial EI Peruano, 15 de junio.

(1982). Decreto Supremo 395-82. Texto Único Ordenado del Código Tributario. Diario Oficial El Peruano, 30 de diciembre.

(1982). Decreto Supremo N031-82-EMVM. Reglamento de la Ley General de Electricidad. Diario Oficial El Peruano, 1 de setiembre.

(1983). Decreto Supremo 003-83-TR. Diario Oficial El Peruano, 19 de febrero.

(1991). Decreto Legislativo $N^{\circ} 702$. Se crea el Organismo Supervisor de la Inversión en Telecomunicaciones - OSIPTEL. Diario Oficial EI Peruano, 8 de noviembre.

(1992). Decreto Ley Nº 25965. Se crea la Superintendencia Nacional de Servicios de Saneamiento (SUNASS). Diario Oficial EI Peruano, 19 de diciembre.

(1992b). Decreto Ley Nº 25868. Ley de organización y funciones del Instituto Nacional de Defensa de la Competencia y de la Protección de la Propiedad Intelectual (INDECOPI). Diario Oficial El Peruano, 18 de noviembre.

(1997). Decreto Supremo N ${ }^{\circ} 029$ 97-EM. Reglamento de Fiscalización de las Actividades Energéticas por terceros. Diario Oficial El Peruano, 12 de diciembre.

(2008). Decreto Legislativo $N^{\circ} 1033$. Ley de organización y funciones del Instituto Nacional de Defensa de la Competencia y de la Protección de la Propiedad Intelectual (INDECOPI). Diario Oficial El Peruano, 24 de junio.

(2008). Decreto Legislativo $N^{\circ} 1013$ Ley que aprueba la Creación, Organización y Funciones del Ministerio del Ambiente. Diario Oficial El Peruano. 13 de mayo.

. (2009). Decreto Supremo Nº17-2009. MTC. Reglamento Nacional de Administración de Transporte. Diario Oficial El Peruano, 21 de abril.

(2013). Decreto Legislativo $N^{\circ} 1158$. Medidas destinadas al fortalecimiento y cambio de denominación de la Superintendencia Nacional de Aseguramiento en Salud. Diario Oficial EI Peruano, 6 de diciembre. 
(2014). Decreto Supremo $N^{\circ}$ 012-2014-MINEDU. Reglamento de Organización y Funciones de la SUNEDU. Diario Oficial EI Peruano, 31 de diciembre.

(2015). Decreto Supremo $N^{\circ} 034$ 2015-SA. Reglamento de Supervisión de Superintendencia Nacional de Salud. Diario Oficial El Peruano, 21 de octubre.

. (2016). Decreto Legislativo $N^{\circ} 1280$. Ley Marco de la Gestión y Prestación de los Servicios de Saneamiento. Diario Oficial El Peruano, 28 de diciembre.

(2016b). Decreto Legislativo $N^{\circ} 1272$ que modifica la Ley $\mathrm{N}^{\circ} 27444$, Ley de Procedimiento Administrativo general y deroga la Ley $\mathrm{N}^{\circ} 29060$, Ley del Silencio Administrativo. Diario Oficial El Peruano, 20 de diciembre.

Rebollo, M. y otros (2017). Derecho Administrativo. Modos y medios de la actividad administrativa (Tomo III). Madrid: Tecnos.

Sánchez Morón, M. (2017). Derecho Administrativo (Decimotercera edición). Madrid: Tecnos.

Sánchez Povis, L. (2019). El enfoque preventivo y la labor educadora de la fiscalización administrativa en el TUO de la Ley del Procedimiento Administrativo General. En Zegarra Valdivia, D (coordinador), La proyección del Derecho Administrativo Peruano. Estudios por el Centenario de la Facultad de Derecho de la PUCP (p. 445-466). Lima: Palestra.

SENACE (2016). ABC del SENACE. Consulta: 15 de abril de 2020. https://www.senace.gob.pe/ wp-content/uploads/2016/10/ABCdelSenace.pdf

Superintendencia Nacional de Servicios de Saneamiento (2004). Resolución de Consejo Directivo N015-2004-SUNASS-CD. Reglamento de Supervisión y Fiscalización de la Prestación de Servicios de Saneamiento. Diario Oficial El Peruano, 13 de junio.

(2007). Resolución de Consejo Directivo N 003-2007-SUNASS-CD. Aprueban el Reglamento General de Supervisión y Fiscalización y Sanción de las EPS. Diario Oficial El Peruano, 18 de enero.

SUNEDU (2017). Resolución de Consejo Directivo N006-2017-SUNEDU-CD. Reglamento de
Supervisión de la SUNEDU. Diario Oficial EI Peruano, 2 de febrero.

Tassano Velaochaga, H. (2008). Los Organismos Reguladores de Servicios Públicos. Revista Círculo de Derecho Administrativo 4, PUCP, p. 89-106.

(2010). Tribunal especial económico como última instancia en asuntos regulatorios de servicios públicos. En Céspedes, A. IV Congreso Nacional de Derecho Administrativo. Modernizando el Estado para un país mejor. Lima: Palestra Editores. p. 369-391.

Thornberry, G. El nuevo papel del regulador de telecomunicaciones. En Revista de Derecho Administrativo. $N^{\circ} 5$, p. 36-44.

Tirado Barrera, J.A. (2011). Reflexiones en Torno a la Potestad de Inspección o Fiscalización de la Administración Pública. Derecho \& Sociedad, 37, p. 251-262. Recuperado de: http://revistas.pucp.edu.pe/ index.php/derechoysociedad/article/view/13177/13790

Tovar Mena, T. (2006). Derecho de la Competencia y Telecomunicaciones. Lima: Ara Editores.

Toyama Miyagusuku, J. (2001). Los derechos laborales en las Constituciones de 1979 y 1993. En Balance de la Reforma Laboral Peruana. Sociedad Peruana de Derecho del Trabajo y la Sociedad Social, Lima, 10.

Tribunal Constitucional del Perú (2008). Sentencia recaída en el expediente 04168-2006-PA/TC. Caso Fernando Samuel Enrique Vásquez Wong. 24 de setiembre. Recuperado de: https://tc.gob.pe/ jurisprudencia/2008/04168-2006-AA.pdf

(2009). Sentencia recaída en el expediente 02389-2009PA/TC. Caso Asociación Club Petróleos- Petroperú. 7 de diciembre. Recuperado de: https://www.tc.gob.pe/jurisprudencia/2009/023892009-AA.html

(2004). Sentencia recaída en el expediente 0858-2003-AA/ TC. Caso Eyler Torres del Águila. 24 de marzo. Recuperado de: https:// www.tc.gob.pe/jurisprudencia/2004/00858-2003-AA.html

(2015). Sentencia recaída en los expedientes 0014-2014 P1/TC, 0016-2014-PI/TC, 0019-2014-P1/TC y 0007-2015-PI/TC. Caso Ley Universitaria. 10 de noviembre. Recuperado de: https://www. tc.gob.pe/jurisprudencia/2015/00014-2014-AI\%2000016-2014-AI\%20 00019-2014-Al\%2000007-2015-AI.pdf

Zegarra Valdivia, D. (2018). La definición de la actividad de fiscalización en la Ley de Procedimiento Administrativo General peruana. En Morón y Danós (Coordinadores). Estudios de Derecho Administrativo. El Derecho Administrativo Iberoamericano. Innovación y reforma. Tomo I (p. 237-246). Lima: Gaceta Jurídica.

Zegarra, D. (2008). El marco institucional y normativo del Organismo Supervisor de la Inversión Privada en Telecomunicaciones - OSIPTEL. En Revista de Derecho Administrativo. N 5, p. 132-149. 